Research Article

\title{
Application of DICM on Similar Material Simulation Experiment for Rock-Like Materials
}

\author{
Hailing Kong $\mathbb{D}^{1,2}$ Luzhen Wang $\mathbb{D}^{1,2}$ Guoqing Gu, ${ }^{1,}$ and Bing $X u \mathbb{D}^{1}$ \\ ${ }^{1}$ Civil Engineering Department, Yancheng Institute of Technology, Yancheng, Jiangsu 224051, China \\ ${ }^{2}$ School of Civil, Environmental and Mining Engineering, The University of Adelaide, Adelaide, SA 5005, Australia
}

Correspondence should be addressed to Luzhen Wang; wangluzhen5@126.com

Received 20 December 2017; Accepted 5 March 2018; Published 2 April 2018

Academic Editor: Yixian Wang

Copyright ( 2018 Hailing Kong et al. This is an open access article distributed under the Creative Commons Attribution License, which permits unrestricted use, distribution, and reproduction in any medium, provided the original work is properly cited.

The digital image correlation method (DICM) has been applied to similar material simulation experiments for rock-like materials, to overcome the weakness of traditional measurements, for example, data discontinuous. In this paper, the movement and fracturing process of the overlying strata during excavation are observed and studied, and the distributions of stress, strain, and deformation in the overlying strata are obtained based on similar material simulation. The DICM is applied to improve the testing method and to optimize the discontinuity of testing points; of course, the difference of rock deformation in the overlying strata during excavation is considered. Full-field deformation and strain are analyzed by the DICM. To verify the accuracy of the DICM, results obtained from the DICM, numerical simulation and similar material simulation, are compared. The DICM can reflect the characteristics of locality and randomness of rock-like materials more real than numerical simulation, and comparing with similar material simulation, it can directly reproduce the movement and fracturing process of the overlying strata during full-field excavation. It shows that, the DICM is entirely feasible to using in the large scale full-field deformation measurement on complex rock structure, and it is of theoretical importance for testing for rock-like materials.

\section{Introduction}

Currently, geotechnical engineering, such as tunneling excavation, landslide treatment, and mining, develops rapidly. For rock-like materials, testing techniques and methods become increasingly important. Similar material simulation is one of the traditional deformation measurements for rocklike materials, but it still has some difficulties, for instance, the obtained data are discontinuous, because we cannot arrange too many testing sensors, otherwise they will affect the stability of the structure.

At present, optical full-field measurement methods, such as digital image correlation method (DICM), are increasingly used in experimental mechanics, especially in the field of testing rock-like materials. The DICM can measure the deformation field on the surface of rock mass when the external factors change. It has the advantages of full-field, noncontact, and relatively simple operation. The DICM needs testing points on the surface of the model, which we can arrange as more as we want, and fortunately, the arrangement has nearly no effect on the structure's stability so that the DICM is probably a more appropriate choice for rock-like materials' measurements.

The DICM, which was picked up by Yamaguchi [1], Peters and Ranson [2], and Peters et al. [3] in the early 1980s, is promising in using for full-field deformation measure of materials and structures, and its applications are the concerns of the majority of scholars, especially in the field of geotechnical engineering.

In recent years, many scholars studied the deformation, crack propagation, damage, and failure process of rock-like materials in plates by the DICM [4-14]. Zhao et al. [4] used the DIC technique to test the deformation field of the rock material plate with the size of $25 \times 13 \times 1.1 \mathrm{~mm}$ containing microcracks and found that the deformation varied in different areas separated by subcracks, which implied the effect of crack opening and closing in rock. Hao et al. [5, 6] described the deformation localization during the fracturing 
process of rock material specimens with the dimensions of $20 \times 16 \times 40 \mathrm{~mm}$ based on DIC and found that the size of the localized zone decreased from the sample size at peak load to an eventual value. Yang et al. [7] and Yang and Jing [8] analyzed the fracture coalescence behavior of rock, tested rectangular prismatic sandstone specimens with the dimensions of $80 \times 160 \times 30 \mathrm{~mm}$, containing three fissures under uniaxial compression, and discussed the strain field evolution and law of crack propagation by DIC. Zhao et al. [9] researched failure process of rock-like materials with the dimensions of $100 \times 100 \times 10 \mathrm{~mm}$ with an open-hole imperfection by numerical and DIC investigations. Ma et al. [10] tested the failure process of granite plate with the dimensions of $60 \times 20 \times 120 \mathrm{~mm}$ containing a hole at its center under uniaxial compression by 3D-DIC. Gao et al. [11, 12] applied the DICM in dynamic notched semicircular bend tests of brittle material plate with the diameter of $25 \mathrm{~mm}$ and considered that the optical method of DIC provided much more information on the fracture propagation process. Ma et al. $[13,14]$ used DIC to study the damage of a rock Brazilian disc with the diameter of $20.35 \mathrm{~mm}$ and height of $6.5 \mathrm{~mm}$ and showed that the failure process of the disc specimen in the Brazilian test was not simple crack propagation under tensile load, but a complicated damage evolution procedure.

The DICM was also used to test rock-like material cylinders [15-18] and blocks [19-28] in small scales. Dautriat et al. $[15,16]$ observed the deformation field evolution of limestone cylinders under different scales in compression experiment by the DICM. Cheng et al. [17] carried out the uniaxial compression tests on a series of composite rock specimens with different dip angles, whose diameter was $150 \mathrm{~mm}$ and height was $500 \mathrm{~mm}$, and found that the specimens had obvious plastic deformation during loading and the brittleness of the specimens gradually increased during the loading process. Hedan et al. [18] analyzed deformation mechanisms induced by desiccation in Tournemire argillite specimens with a height of $200 \mathrm{~mm}$ and a diameter of $78 \mathrm{~mm}$ using the DICM.

$\mathrm{Li}$ et al. [19] combined the digital image processing technology and RFPA-DIP to establish a numerical model of flawed granite with the dimensions of $100 \times 100 \mathrm{~mm}$, which reflected the real mesoscale behaviors of material accurately, and studied the influences of diverse mineral particle structures and flaws on the mesofracture behaviors. Yang et al. $[20,21]$ presented an experimental study on the delayed behavior of unsaturated argillaceous rocks with the dimensions of $24 \times 36 \mathrm{~mm}$, including shrinkage, swelling, and creep, by DIC techniques and measured the very low strain rate of the argillaceous rocks at various scales under uniaxial compression and various environmental conditions. Wang et al. [22-24] measured shear bands of sand specimens with different water contents under constant strain rate based on the DICM. Zinsmeister et al. [25] studied the mechanical evolution of an altered limestone by the DICM (2D and 3D) and observed a transition from brittle to ductile failure mechanisms with the alteration level. To compare and discuss the values of strains and crack apertures associated with desiccation cracks measured in Tournemire clay rock at different scales (micrometer to decimeter), Fauchille et al. [26-28] used the DICM to research the relationships between desiccation cracking behavior and microstructure of the Tournemire clay rock.

Some scholars improved the DICM based on rock-like material tests in small scales [29-33]. Chen et al. [29] presented a two-dimensional digital image based on the numerical modeling method for heterogeneous geomaterials. Yue [30] presented that the digital image processing method could be used as a measurement tool to construct a digital representation for the actual spatial distribution of the different materials and components in geomaterial samples, which was further proceeded to automatically generate meshes or grids for numerical analysis. Bornert et al. [31] studied deformation and failure of clay rock under different humidity and discussed various error regimes, including the dependence of the uncertainty with the parameters of the algorithms. Nguyen et al. [32] analyzed the fracture evolution from inclined flaws (cuts) in a soft rock deformed under plane-strain uniaxial compression by high-resolution digital photographs and developed the extended DICM to allow automatic tracing of discontinuities and their quantification in terms of the displacement jumps along their length. Valle et al. [33] used an improved DIC procedure to perform an evaluation of the displacement where multiple cracks presented and applied in argillite rock to validate the efficiency and the robustness. Chen et al. [34] used 3D-DIC to elucidate the effect of aggregate size and volume on the nonuniform strain distribution in concrete. Su et al. [35] studied the stress-strain relationship and cohesion model parameters in concrete- and mortarbonded composite specimens from the interface displacement and distribution of strain.

References [4-35] show that the DICM is satisfactory in small deformation measurement for rock-like materials' experiments.

Currently, a few scholars focused on the application of DICM on large-scale tests [36-38]. Mao et al. [36, 37] proposed the digital target marker image correlation method for improving the measurement efficiency of model displacement, recorded the different displacement phase images of model, used the correlation searching to confirm the marker coordinates, and obtained the displacements of markers. Guo et al. [38] applied the DICM to measure displacement of the measured points in similar material simulation experiment. However, testing target markers on the surface of the similar material simulation models in the studies of Mao et al. and Guo et al. [36-38] were arranged uniformly, which ignored the difference of rock deformation in the overlying strata during excavation.

For rock-like materials, similar material simulation experiment is a kind of testing technology of very common and wide-range application for large-scale experiments. In this paper, the DICM is applied in similar material simulation experiment to test movement and deformation of the overlying strata during excavation; testing points' arrangement is optimally designed considering the difference of rock deformation in the overlying strata during excavation; and the accuracy of DICM is verified by comparing results obtained from the DICM, similar material simulation and numerical simulation. 
TABLE 1: Parameters of coal rock materials and the similar material simulation match.

\begin{tabular}{|c|c|c|c|c|c|c|c|c|}
\hline Number & Lithology & $\begin{array}{l}\text { Stratum } \\
\text { thickness (m) }\end{array}$ & $\begin{array}{l}\text { Compressive } \\
\text { strength (MPa) }\end{array}$ & $\begin{array}{l}\text { Density } \\
\left(\mathrm{kg} / \mathrm{m}^{3}\right)\end{array}$ & $\begin{array}{c}\text { Sand } \\
(\mathrm{kg})\end{array}$ & $\begin{array}{l}\text { Gypsum } \\
(\mathrm{kg})\end{array}$ & $\begin{array}{c}\text { Calcium } \\
\text { carbonate }(\mathrm{kg})\end{array}$ & $\begin{array}{c}\text { Water } \\
(\mathrm{kg})\end{array}$ \\
\hline 1 & Shale & 2.20 & 32.50 & $2.35 \times 10^{3}$ & 14.60 & 1.20 & 1.20 & 2.30 \\
\hline 2 & Interbedded shale sandstone & 2.00 & 25.10 & $2.30 \times 10^{3}$ & 12.70 & 1.00 & 1.10 & 2.00 \\
\hline 3 & Shale & 1.30 & 32.40 & $2.34 \times 10^{3}$ & 8.20 & 0.70 & 0.70 & 1.30 \\
\hline 4 & Laminated sandstone & 1.70 & 36.60 & $2.28 \times 10^{3}$ & 10.70 & 1.10 & 0.90 & 1.70 \\
\hline 5 & Medium-grained sandstone & 4.20 & 27.10 & $2.40 \times 10^{3}$ & 25.80 & 2.00 & 2.20 & 4.20 \\
\hline 6 & Laminated sandstone & 3.40 & 39.30 & $2.41 \times 10^{3}$ & 21.20 & 2.00 & 1.80 & 3.40 \\
\hline 7 & Medium-grained sandstone & 2.70 & 35.10 & $2.35 \times 10^{3}$ & 13.10 & 1.70 & 1.70 & 2.80 \\
\hline 8 & Interbedded shale sandstone & 2.00 & 20.10 & $2.39 \times 10^{3}$ & 12.70 & 1.00 & 1.20 & 2.00 \\
\hline 9 & Shale & 2.50 & 35.40 & $2.28 \times 10^{3}$ & 12.70 & 1.10 & 1.10 & 2.50 \\
\hline 10 & Interbedded shale sandstone & 1.70 & 24.40 & $2.34 \times 10^{3}$ & 10.80 & 1.00 & 0.90 & 1.70 \\
\hline 11 & $\begin{array}{l}\text { Middle-grained sandstone } \\
\text { intercalated with shale }\end{array}$ & 2.00 & 35.10 & $2.32 \times 10^{3}$ & 13.90 & 1.10 & 1.30 & 2.00 \\
\hline 12 & Medium-grained sandstone & 2.00 & 23.90 & $2.42 \times 10^{3}$ & 12.70 & 1.10 & 1.10 & 2.00 \\
\hline 13 & Laminated sandstone & 1.50 & 32.10 & $2.30 \times 10^{3}$ & 8.90 & 0.70 & 0.70 & 1.40 \\
\hline 14 & Interbedded shale sandstone & 1.80 & 39.40 & $2.41 \times 10^{3}$ & 11.40 & 1.20 & 0.90 & 1.80 \\
\hline 15 & Medium-grained sandstone & 2.20 & 29.40 & $2.52 \times 10^{3}$ & 15.20 & 1.30 & 1.30 & 2.70 \\
\hline 16 & Shale & 3.60 & 30.30 & $2.3 \times 10^{3}$ & 23.50 & 1.90 & 1.90 & 3.70 \\
\hline 17 & Interbedded shale sandstone & 2.00 & 34.50 & $2.17 \times 10^{3}$ & 14.60 & 1.2 & 1.20 & 2.30 \\
\hline 18 & Shale & 2.50 & 35.40 & $2.28 \times 10^{3}$ & 12.70 & 1.10 & 1.10 & 2.50 \\
\hline 19 & Medium-grained sandstone & 2.00 & 34.50 & $2.17 \times 10^{3}$ & 12.70 & 1.10 & 1.00 & 2.00 \\
\hline 20 & Shale & 4.00 & 25.50 & $2.60 \times 10^{3}$ & 25.30 & 2.00 & 2.20 & 4.00 \\
\hline 21 & $\begin{array}{l}\text { Middle-grained sandstone } \\
\text { intercalated with shale }\end{array}$ & 2.00 & 43.80 & $2.42 \times 10^{3}$ & 12.70 & 1.00 & 1.20 & 2.00 \\
\hline 22 & Interbedded shale sandstone & 1.70 & 29.50 & $2.52 \times 10^{3}$ & 10.80 & 1.00 & 0.90 & 1.70 \\
\hline 23 & Shale & 4.50 & 32.30 & $2.38 \times 10^{3}$ & 28.5 & 2.30 & 2.50 & 4.50 \\
\hline 24 & Medium-grained sandstone & 0.80 & 35.20 & $2.35 \times 10^{3}$ & 5.10 & 0.40 & 0.40 & 0.80 \\
\hline 25 & Sandstone & 0.90 & 36.80 & $2.36 \times 10^{3}$ & 5.70 & 0.60 & 0.40 & 0.90 \\
\hline 26 & Laminated sandstone & 0.80 & 48.10 & $2.32 \times 10^{3}$ & 5.10 & 0.40 & 0.40 & 0.80 \\
\hline 27 & Interbedded shale sandstone & 5.30 & 32.40 & $2.34 \times 10^{3}$ & 33.60 & 2.80 & 2.80 & 5.30 \\
\hline 28 & $\begin{array}{l}\text { Medium-grained sandstone (the } \\
\text { thin overlying hard rock) }\end{array}$ & 2.00 & 29.40 & $2.36 \times 10^{3}$ & 12.70 & 1.10 & 1.00 & 2.00 \\
\hline 29 & Shale & 4.00 & 43.20 & $2.44 \times 10^{3}$ & 25.30 & 2.00 & 2.20 & 4.00 \\
\hline 30 & Laminated sandstone & 3.60 & 43.90 & $2.36 \times 10^{3}$ & 22.80 & 2.00 & 1.80 & 3.60 \\
\hline 31 & Medium-grained sandstone & 1.10 & 21.50 & $2.28 \times 10^{3}$ & 7.00 & 0.60 & 0.60 & 1.10 \\
\hline 32 & Shale & 1.30 & 36.60 & $2.28 \times 10^{3}$ & 8.20 & 0.70 & 0.70 & 1.30 \\
\hline 33 & Laminated sandstone & 2.00 & 27.10 & $2.4 \times 10^{3}$ & 12.70 & 1.10 & 1.10 & 2.00 \\
\hline 34 & Medium-grained sandstone & 9.10 & 20.00 & $2.3 \times 10^{3}$ & 57.60 & 4.40 & 5.20 & 9.10 \\
\hline 35 & Laminated sandstone & 2.00 & 24.40 & $2.34 \times 10^{3}$ & 12.70 & 1.00 & 1.20 & 2.00 \\
\hline 36 & $\begin{array}{l}\text { Medium-grained sandstone (the } \\
\text { thick overlying hard rock) }\end{array}$ & 23.60 & 35.50 & $2.28 \times 10^{3}$ & 152.50 & 11.00 & 11.00 & 23.90 \\
\hline 37 & Coal (excavated $)$ & 5.00 & 14.00 & $1.48 \times 10^{3}$ & 32.30 & 2.30 & 2.30 & 5.10 \\
\hline 38 & $\begin{array}{l}\text { Middle-grained sandstone } \\
\text { intercalated with shale }\end{array}$ & 2.00 & 39.50 & $2.39 \times 10^{3}$ & 12.70 & 10.00 & 1.20 & 2.00 \\
\hline 39 & Interbedded shale sandstone & 7.00 & 25.10 & $2.40 \times 10^{3}$ & 44.40 & 3.70 & 3.70 & 7.10 \\
\hline 40 & Medium-grained sandstone & 6.00 & 43.70 & $2.42 \times 10^{3}$ & 38.00 & 3.20 & 3.20 & 6.10 \\
\hline
\end{tabular}

\section{Similar Material Simulation Experiment}

2.1. Similar Material Simulation Prototype. This simulation model in this paper originates from no. 1 borehole of the VI strata in a coal field in North China. Based on the strata histogram, there are 40 strata in this borehole histogram, and the total strata thickness is $132 \mathrm{~m}$ except topsoil. The parameters of coal rock materials of each stratum, such as lithology, stratum thickness, compressive strength, and density, are listed in Table 1. The coal rock materials of the prototype are simulated by sand, gypsum, calcium carbonate, and water, and the match is also listed in Table 1.
Obviously, no. 37 stratum is coal, with a wholly mining height of $5 \mathrm{~m}$, which will be excavated; nos. 38 40 strata are floors, and nos. 1 36 strata are roofs, among which, no. 28 stratum (medium-grained sandstone) is the thin overlying hard rock, nos. 29 35 strata are the overlying soft rock, and no. 36 stratum (medium-grained sandstone) with a height of $23.6 \mathrm{~m}$ is the thick overlying hard rock.

\subsection{Similar Conditions}

2.2.1. Geometrical Similarity. The geometrically similar rate of the simulation model is 


$$
C_{\mathrm{L}}=\frac{L_{\mathrm{p}}}{L_{\mathrm{m}}}=100
$$

where $C_{\mathrm{L}}$ is the geometrically similar rate and $L_{\mathrm{p}}$ and $L_{\mathrm{m}}$ are the length of prototype and the similar material simulation model, respectively.

2.2.2. Material Similarity. Based on the densities of coal rock materials of strata in the prototype and the similar material, the material similar rate is

$$
C_{\rho}=\frac{\rho_{\mathrm{p}}}{\rho_{\mathrm{m}}}=1.7
$$

where $C_{\rho}$ is the material similar rate and $\rho_{\mathrm{p}}$ and $\rho_{\mathrm{m}}$ are the density of prototype and the similar material simulation model, respectively.

Theoretically, the stress similar rate is

$$
C_{\sigma}=\frac{\sigma_{\mathrm{p}}}{\sigma_{\mathrm{m}}}=\frac{L_{\mathrm{p}}}{L_{\mathrm{m}}} \cdot \frac{\gamma_{\mathrm{p}}}{\gamma_{\mathrm{m}}}=\frac{L_{\mathrm{p}}}{L_{\mathrm{m}}} \cdot \frac{\rho_{\mathrm{p}}}{\rho_{\mathrm{m}}}=C_{\mathrm{L}} \cdot C_{\rho}=170,
$$

where $C_{\sigma}$ is the stress similar rate and $\sigma_{\mathrm{p}}, \sigma_{\mathrm{m}}, \gamma_{\mathrm{p}}$, and $\gamma_{\mathrm{m}}$ are, respectively, the stress and the weight of prototype and the similar material simulation model.

Further, because strain is dimensionless and $\varepsilon_{\mathrm{p}}=\varepsilon_{\mathrm{m}}$, the elastic modulus similar rate is

$$
C_{\mathrm{E}}=\frac{E_{\mathrm{p}}}{E_{\mathrm{m}}}=\frac{\sigma_{\mathrm{p}} \varepsilon_{\mathrm{p}}}{\sigma_{\mathrm{m}} \varepsilon_{\mathrm{m}}}=\frac{\sigma_{\mathrm{p}}}{\sigma_{\mathrm{m}}}=170,
$$

where $C_{\mathrm{E}}$ is the elastic modulus similar rate and $E_{\mathrm{p}}, E_{\mathrm{m}}, \varepsilon_{\mathrm{p}}$, and $\varepsilon_{\mathrm{m}}$ are, respectively, the elastic modulus and the strain of prototype and the similar material simulation model.

2.2.3. Dynamic Similarity. The dynamic similarity and external force similarity require all the forces between the prototype and model to be similar and satisfy the following formulas

$$
\begin{gathered}
C_{\mathrm{m}}=\frac{m_{\mathrm{p}}}{m_{\mathrm{m}}}=C_{\rho} \cdot C_{\mathrm{L}}^{3}=1.7 \times 10^{6}, \\
C_{\mathrm{F}}=\frac{F_{\mathrm{p}}}{F_{\mathrm{m}}}=C_{\mathrm{L}}^{3} \cdot C_{\gamma}=1.7 \times 10^{6},
\end{gathered}
$$

where $C_{\mathrm{m}}$ is the mass similar rate, $C_{\mathrm{F}}$ is the force similar rate, and $F_{\mathrm{p}}$ and $F_{\mathrm{m}}$ are the force of prototype and the similar material simulation model, respectively.

Because the Poisson ratio is dimensionless, the Poisson ratio of materials in the similar material simulation model must keep the same with that of the prototype.

2.3. Model Manufacture and Testing Sensor Arrangement. Based on [39-42], the height-width rate of the simulation model is appropriately $5 \sim 8$. Taking into account the plane-strain problem, the height-width rate of this model is set as 6.6. Considering the width of the model frame is $200 \mathrm{~mm}$, the simulation model is manufactured with the dimensions of $2500 \times 1320 \times 200 \mathrm{~mm}$ (Figure 1).

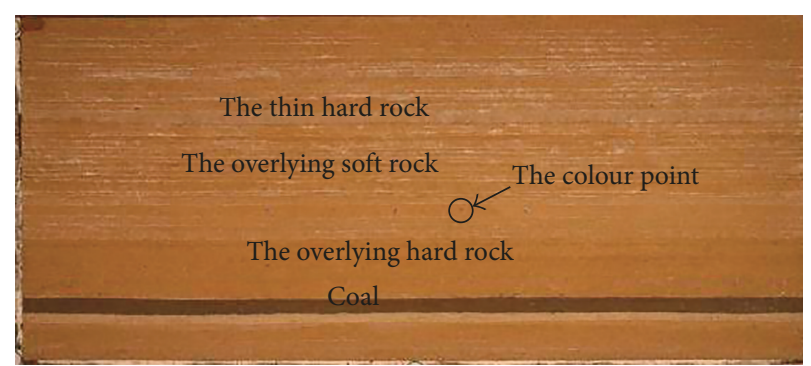

Figure 1: The manufactured similar material simulation model.

During the similar material simulation experiment, the excavation distance of the coal stratum is $1900 \mathrm{~mm}$, excavation space and excavation height are $50 \mathrm{~mm}$, and it will be excavated all height at one time. A $300 \mathrm{~mm}$ coal pillar will remain before the open cut, and another $300 \mathrm{~mm}$ coal pillar is left at the end of goaf (Figure 2).

When the similar material simulation model is manufactured, the weight of excepted topsoil is acting as the additional uniform load on the top of this simulation model, and displacement sensors and pressure sensors are arranged as seen in Figure 2. Four pressure sensors (nos. 1 to 4 ) are buried every $400 \mathrm{~mm}$ in the overlying soft rock, $60 \mathrm{~mm}$ near the thick overlying hard rock; no. 5 is buried above the open cut, $200 \mathrm{~mm}$ away from the coal stratum; and the other six pressure sensors (nos. 6 to 11) are buried every $200 \mathrm{~mm}$ near the position of the initial fracture in the thick overlying hard rock, $100 \mathrm{~mm}$ above the coal stratum. Seven displace sensors (nos. 1 to 7 ) are buried every $300 \mathrm{~mm}$ in a row in the thin overlying hard rock, nos. 8 to 14 are arranged in a row in the overlying soft rock, and nos. 15 to 21 are arranged in a row in the middle of the thick overlying hard rock, and the three rows are distanced every $240 \mathrm{~mm}$. To keep the stability of the model's structure, sensors cannot be arranged any more.

\section{The Results and Analysis of the Similar Material Simulation}

Size unit in the similar material simulation model is millimeter $(\mathrm{mm})$, but results in this paper are analyzed as a practical project so that the size of the model will exaggerate, as well as the excavation of the coal stratum and deformation of the overlying strata. The units of the excavation and deformation appeared in this part are meter $(\mathrm{m})$.

3.1. Failure Forms of Overlying Strata and Fracture Development Characteristics. Once the coal stratum is excavated, the overlying strata fracture gradually, and caving zones, fracture zones, and bend subsidence zones are found in the overlying strata. The failure forms of overlying strata and crack development characteristics in this similar material simulation model are shown in Figure 3.

As the coal stratum is excavated to $120 \mathrm{~m}$ (Figure 3(a)), a longitudinal crack about $12 \mathrm{~m}$ height clearly appears in the thick overlying hard rock, and it tilts to the back of workface. An approximately $45^{\circ}$ crack appears above the open cut, which runs through the thick overlying hard rock. At the 


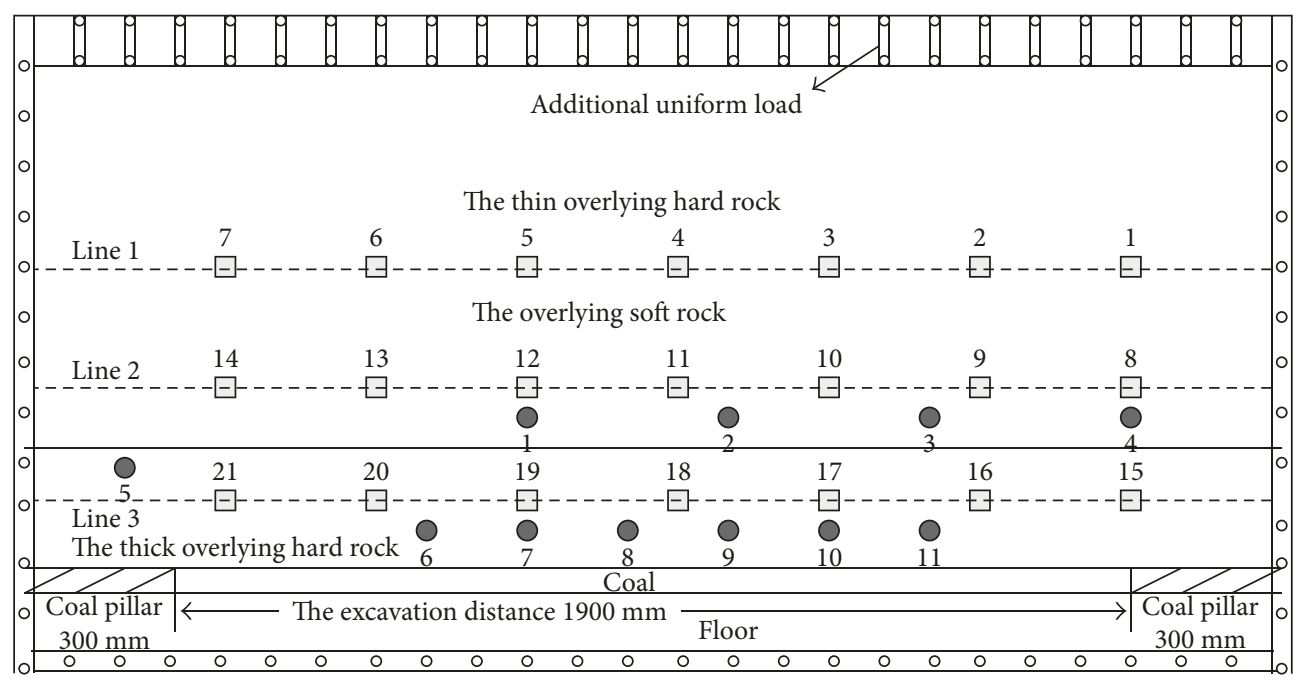

Displace sensor

Pressure sensor

Figure 2: Arrangement of displace sensors and pressure sensors.

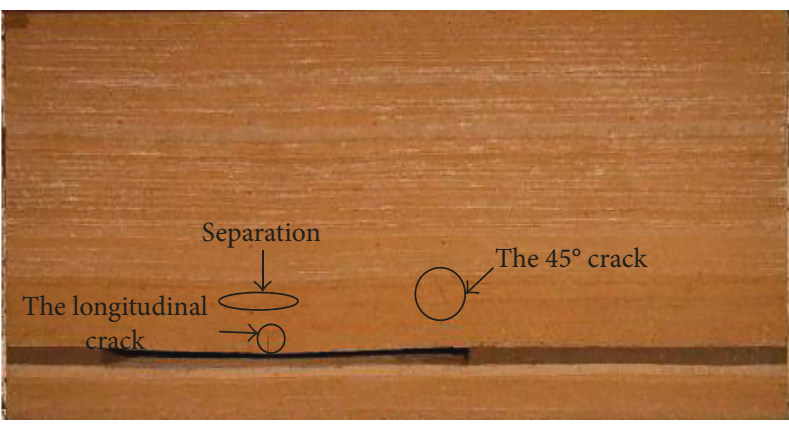

(a)

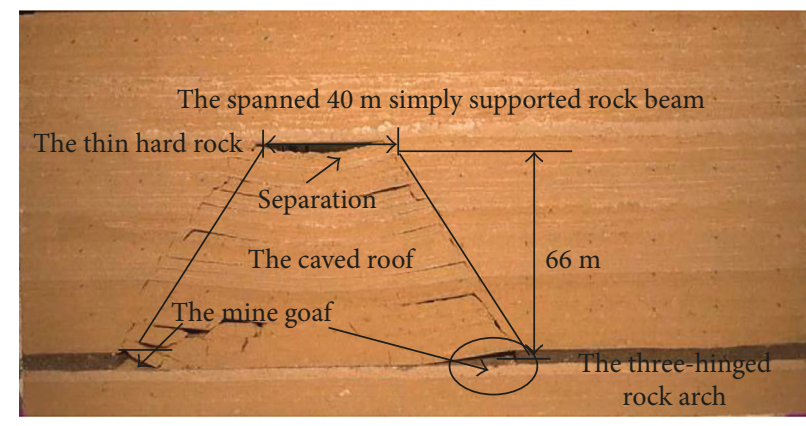

(b)

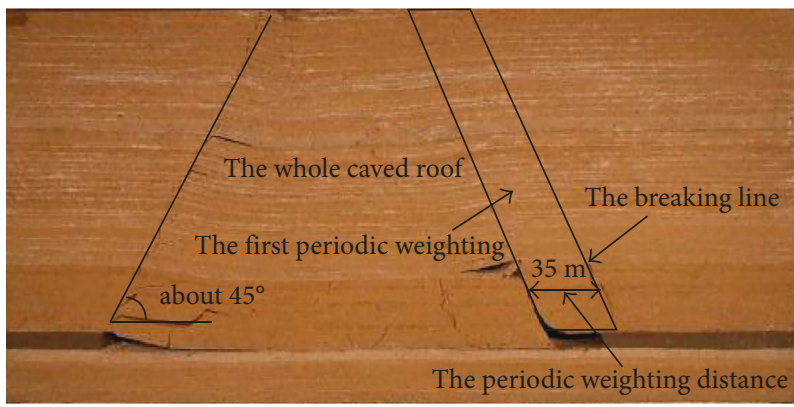

(c)

FIGURE 3: The failure forms of the overlying strata and crack development characteristics during excavation. The coal stratum is excavated to (a) $120 \mathrm{~m}$, (b) $130 \mathrm{~m}$, and (c) $165 \mathrm{~m}$.

same time, a separation appears approximately $36 \mathrm{~m}$ above goaf.

When workface is pushed onto $130 \mathrm{~m}$ (Figure 3(b)), the roof, including the thick overlying hard rock and part of the overlying soft rock, caves suddenly with obvious phenomenon of dynamic pressure. The caved roof has a height of approximately $66 \mathrm{~m}$. A big separation appears between the caved roof and the thin overlying hard rock, and a spanned $40 \mathrm{~m}$ simply supported rock beam is formed. The goaf is almost compacted by the caved roof, and the collapsed rock blocks occlude each other at the open cut, forming a three-hinged rock arch.

With the excavation continuing to $165 \mathrm{~m}$ (Figure 3(c)), the first periodic weighting happens, and the periodic weighting distance is approximately $35 \mathrm{~m}$. Due to the good integrity and continuity of the heave roof (including the thick overlying hard rock and soft rock), the roof fractures and wholly caves, accompanying with obvious dynamic 


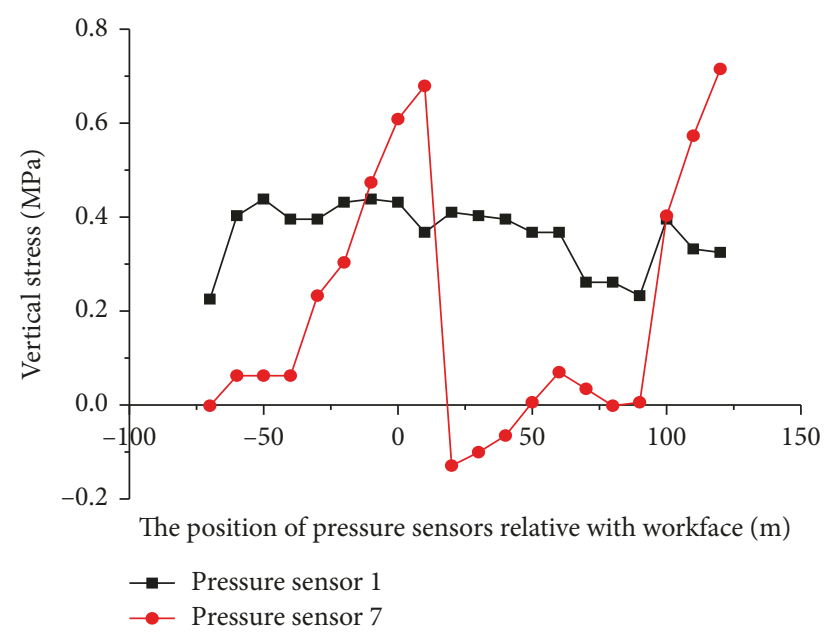

(a)

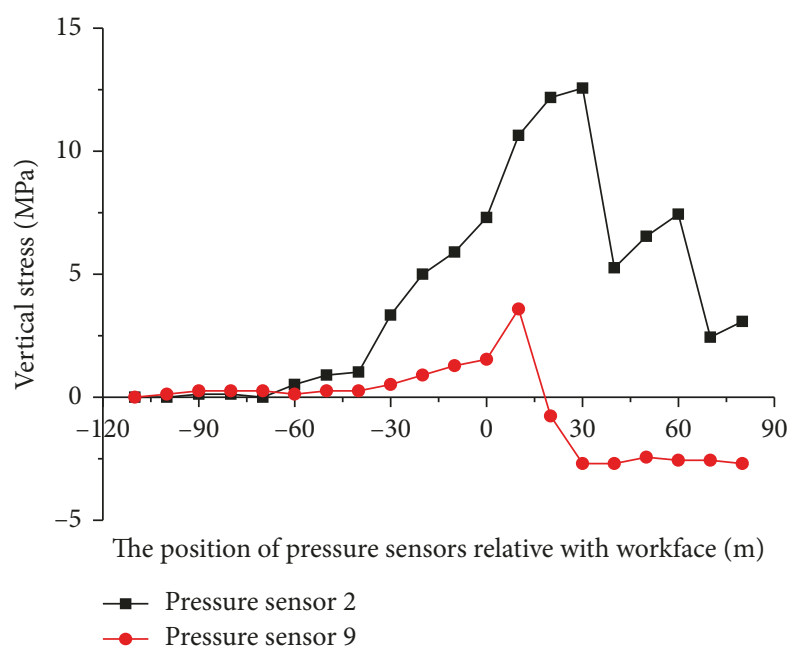

(b)

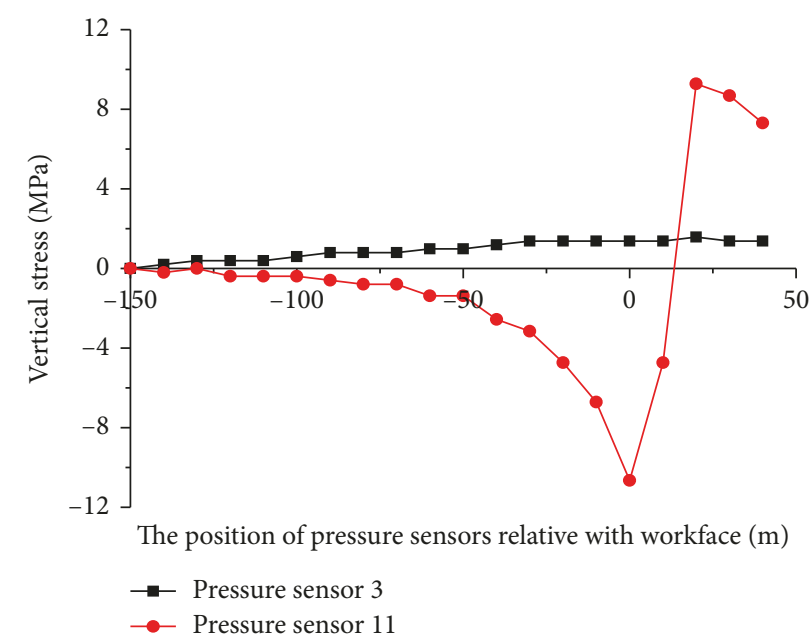

(c)

Figure 4: The distribution rules of stress in the overlying strata during excavation. Pressure sensors (a) 1 and 7, (b) 2 and 9, and (c) 3 and 11.

pressure. The fracturing line locates behind workface, which is approximately $45^{\circ}$ to goaf, as well as the crack at the open cut which runs through the whole roof. The three-hinged rock arch caves, and the separation is compacted.

Combining Figures 3(b) and 3(c), we can find that the overlying strata are controlled by the thick overlying hard rock because the thick overlying hard rock and the overlying strata move synchronously before and after fracturing. So that, whether or not the thick overlying hard rock fractures has direct effect on the fracture of the overlying strata.

3.2. Distribution Rules of Stress in Overlying Strata. The distribution rules of stress in the overlying strata during excavation are tested by pressure sensors (Figure 4). Due to excavation, advancing support pressure appears in front of the coal wall round the workface, especially the area approximately $30 \mathrm{~m}$ in front of the workface, which is affected by excavation most violently, and the advancing support pressure there increases to the peak value till the first periodic weighting happens. The peak value of the advancing support pressure usually appears at about 10 to $20 \mathrm{~m}$ away from coal wall. As the roof is caved, the advancing support pressure decreases gradually. With the excavation continuing, the vertical stress in the roof increases gradually till the next peak value. Because of the loose of the rock strata structure after excavation, the measured stress at some position has little difference with the actual observation.

3.3. Movement Rules of the Overlying Strata. The overlying strata movement rules are tested by displace sensors. Figure 5 shows the varying rules of the overlying strata's subsidence at some position during excavation. The subsiding process of the overlying strata is divided into several stages. In the first stage (Figure 5(a)), the overlying strata keep stable during excavation; the second stage and the third stage are shown in Figures 5(a) and 5(b); in the second stage, with the excavation continuing, the overlying strata's subsidence increase gradually, and the stratum close to coal stratum has larger subsidence; in the third stage, when the first periodic weighting happens, the immediate roof caves suddenly, and 

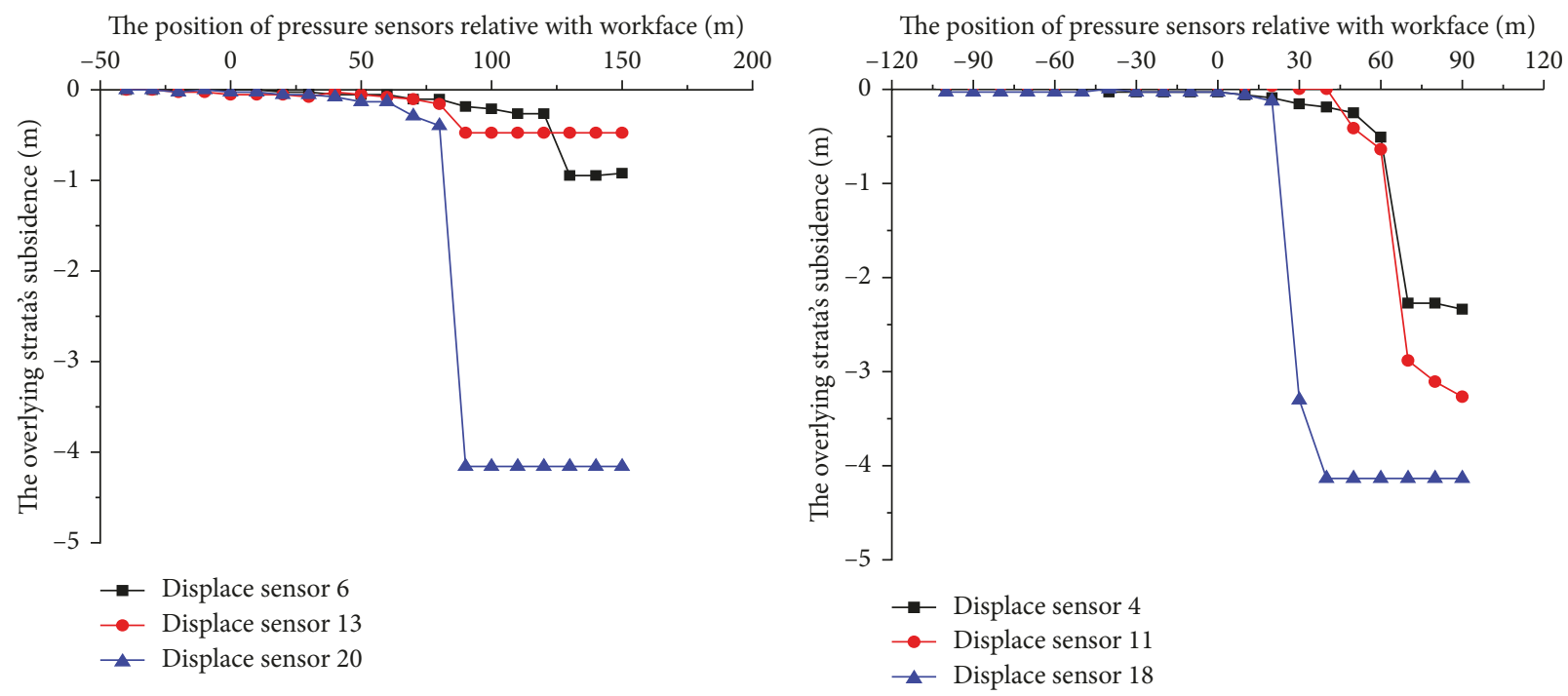

(a)

(b)

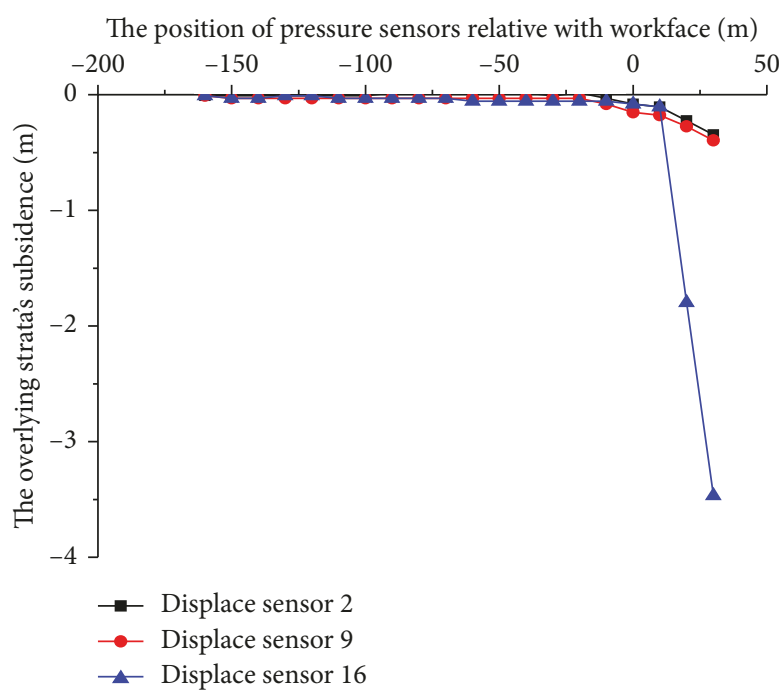

(c)

Figure 5: The overlying strata's subsidence at some position during excavation. Displace sensor (a) 6, 13, and 20, (b) 4, 11, and 18, and (c) 2, 9 , and 16.

the overlying strata's subsidence increase rapidly; in the fourth stage (Figure 5(c)), with the excavation continuing, the goaf is compacted wholly, and the overlying strata's subsidence become stable.

The displace sensor nos. 1 to 7 , nos. 8 to 14 , and nos. 15 to 21 in the overlying hard rock are seemed as the testing line 1, 2 , and 3 , respectively. The varying curves of the overlying strata's subsidence tested by the three testing lines during excavation are showed in Figure 6.

With the excavation continuing to $60 \mathrm{~m}$ (Figure 6(a)), the overlying strata subside simultaneously at a slow speed and form a little and similar subsidence.

When the excavation continues to $130 \mathrm{~m}$ (Figure 6(b)), the roof caves, the subsidence of the thick overlying hard rock and soft rock increases suddenly and simultaneously, but the increments of these two subsidence are different, which shows that the thick overlying hard rock and soft rock fracture simultaneously, a separation appears between them, and another separation appears under the thin overlying hard rock resulting from the thin overlying hard rock bending.

When the coal stratum is excavated $160 \mathrm{~m}$ (Figure 6(c)), before the first periodic weighting, the thin overlying hard rock, the overlying soft rock, and thick overlying hard rock subside suddenly, and the goaf is compacted by the overlying hard rock.

As workface is pushed onto $190 \mathrm{~m}$ (Figure 6(d)), after the first periodic weighting, the thick overlying hard rock and the soft rock subside rapidly and simultaneously.

3.4. Deficiencies of the Similar Material Simulation. Usually, in similar material simulation experiments, testing points (sensors) are arranged and buried before experiments, so the arrangement needs to be designed, which takes time and 


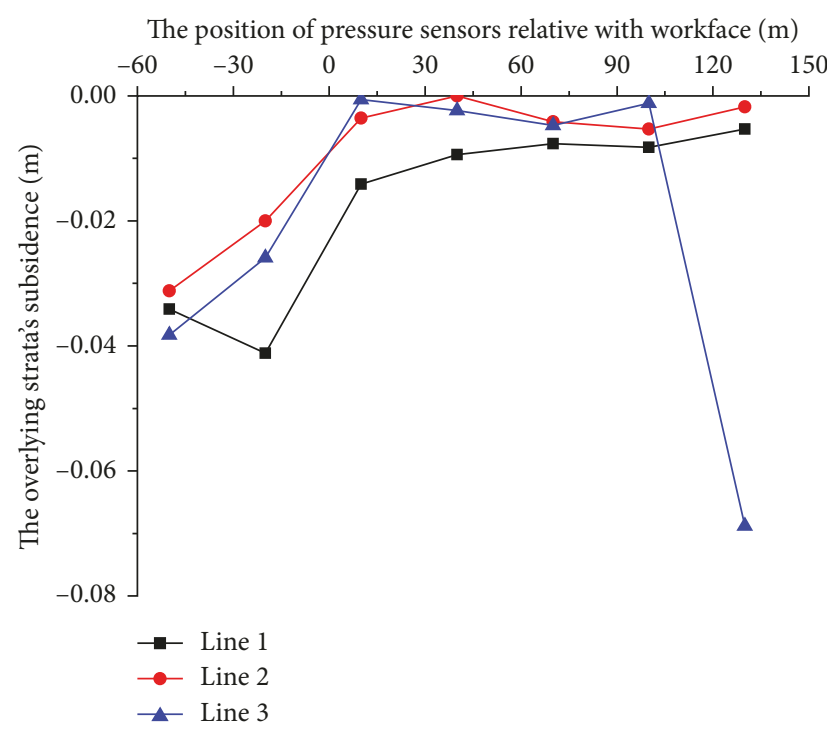

(a)

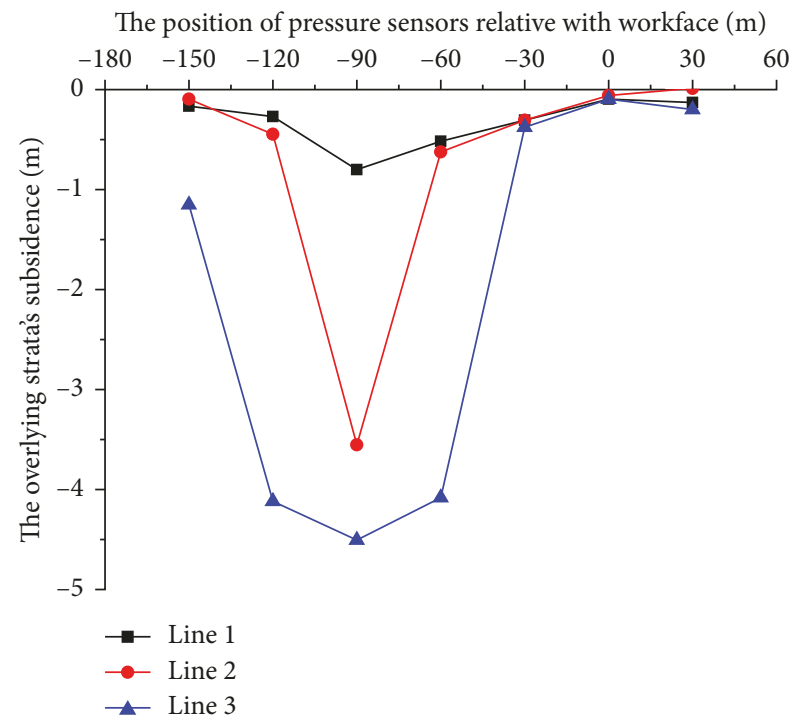

(c)

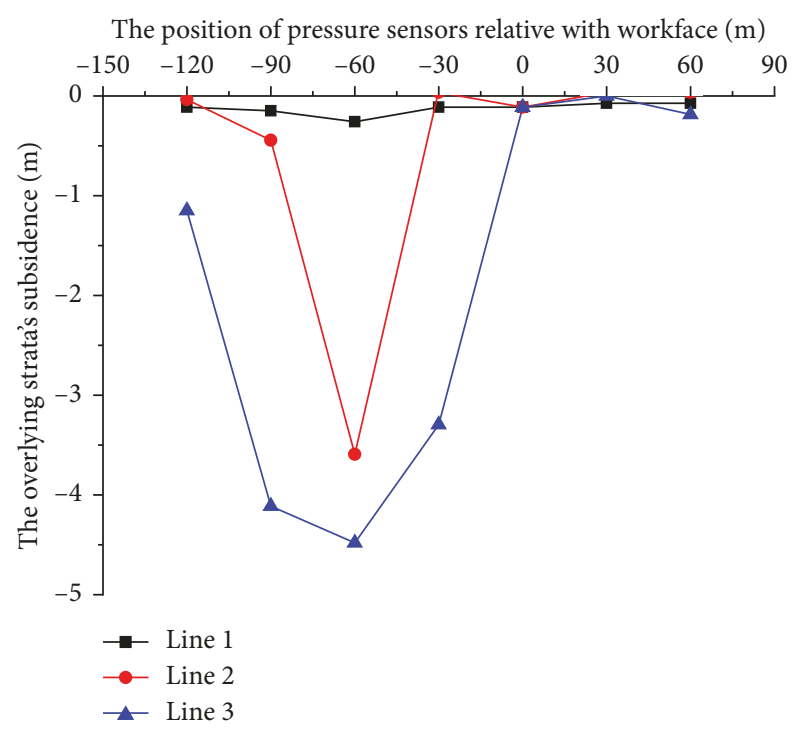

(b)

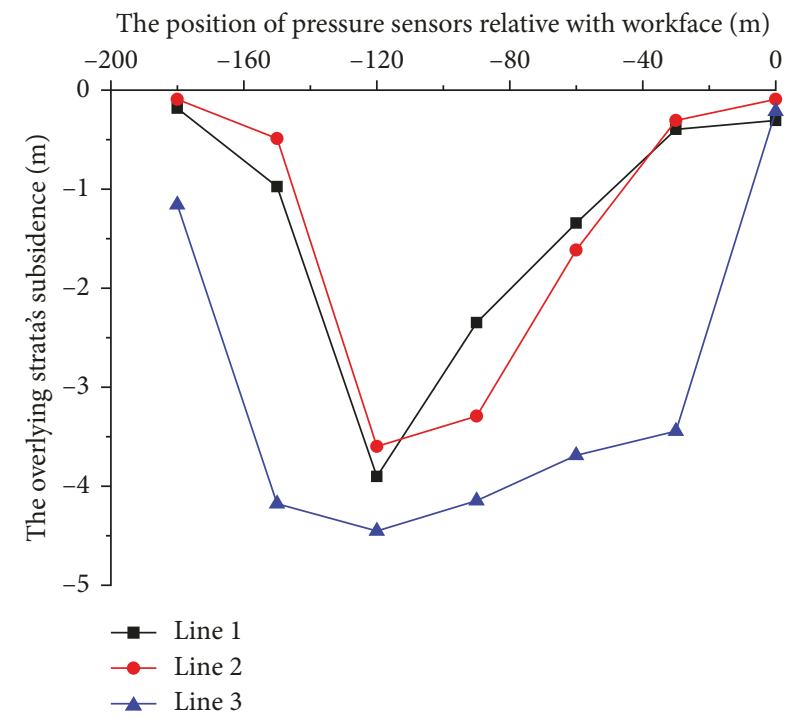

(d)

FiguRE 6: The varying curves of the overlying strata's subsidence during excavation. The coal stratum is excavated to (a) $60 \mathrm{~m}$, (b) $130 \mathrm{~m}$, (c) $160 \mathrm{~m}$, and (d) $190 \mathrm{~m}$.

troubles. Based on the measured data collected by sensors, the stress and deformation of these points are obtained, but these data are scattered points and discontinuous. If more sensors are buried in the model, those sensors will probably have influence on the stability of the model's structure during excavation. So that, obtaining data of every point we want continuously and easily is what we are pursuing.

\section{Testing and Analysis of DICM}

Size unit in the similar material simulation model is millimeter $(\mathrm{mm})$, but results in this paper are analyzed as a practical project so that the size of the model will exaggerate, as well as the excavation of the coal stratum and deformation of the overlying strata. The units of the excavation and deformation appeared in this part are meter $(\mathrm{m})$.
4.1. Testing Point Arrangement on the Similar Simulation Model. Depending on the requirement of the DICM, the control reference points are arranged on the surface of the similar material simulation model because the image coordinates and model coordinates need to be corresponded when the images are analyzed by software. In this model, we choose the lower left quarter of the model as the coordinate origin and choose the horizontally lower boundary and the vertically left boundary as the $X$ axis and $Y$ axis, respectively; select these points, such as $(-32.5 \mathrm{~mm}, 1161 \mathrm{~mm}),(1248 \mathrm{~mm}$, $1160 \mathrm{~mm}),(2548.5 \mathrm{~mm}, 1160 \mathrm{~mm}),(2551.6 \mathrm{~mm}, 0 \mathrm{~mm})$, $(1261.1 \mathrm{~mm}, 0 \mathrm{~mm})$, and $(-32.5 \mathrm{~mm}, 0 \mathrm{~mm})$, as the control reference points (Figure 7).

In order to enhance the correlation between sequences of photographs and to contrast with the colour of similar material simulation model, rows of colour points are arranged 


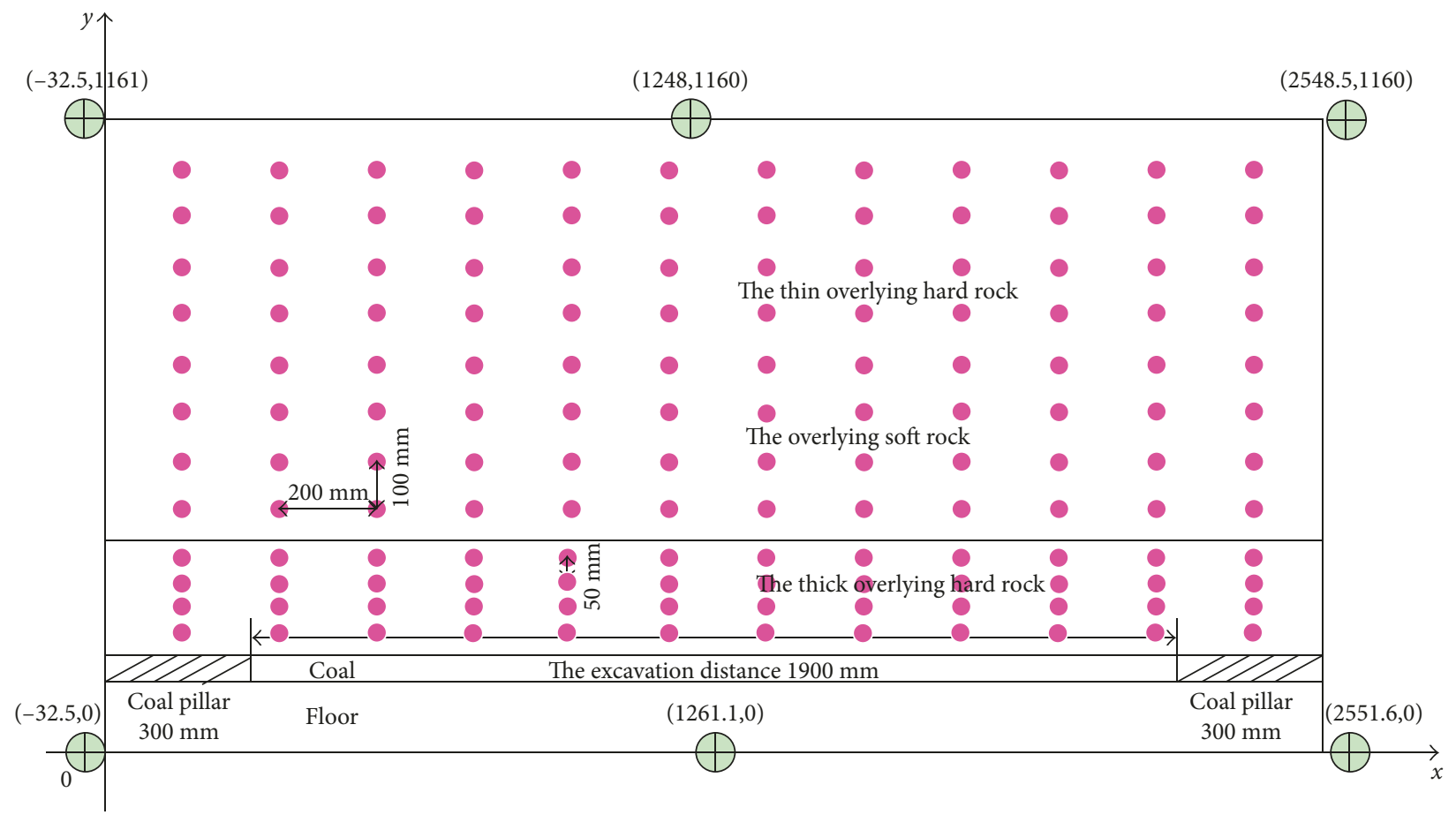

Figure 7: The arrangement of the control reference points and the colour points.

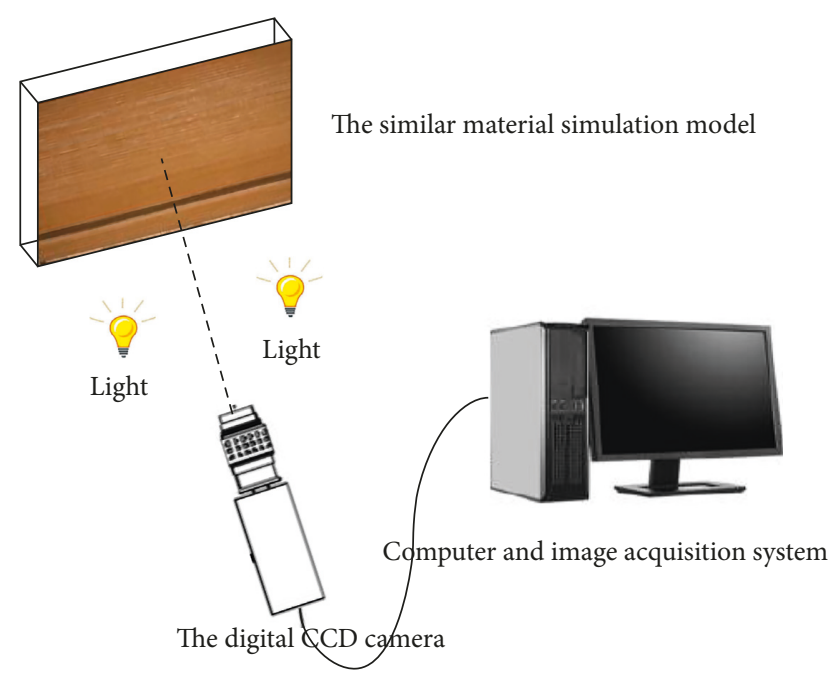

FIgURE 8: The DIC testing system.

every $200 \mathrm{~mm}$ on the surface of the model. Considering the difference of rock deformation in the overlying strata during excavation, four rows are arranged every $50 \mathrm{~mm}$ in the thick overlying hard rock and other rows are arranged every $100 \mathrm{~mm}$ in the roof except the thick overlying hard rock (Figure 7).

4.2. DICM Testing System. The DICM testing system is composed of charge-coupled device (CCD) camera, lights, computer, and the image acquisition system (Figure 8).

The experimental procedures of DICM are as follows: firstly, using the stable lights to get uniform illumination on

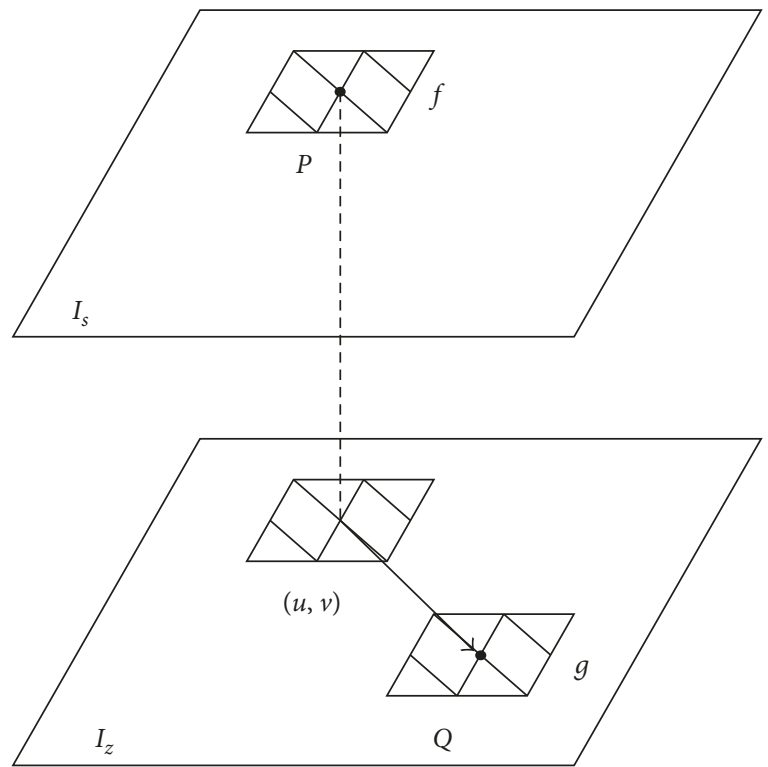

FIGURE 9: Sketch map of correlation analysis.

the model plane; secondly, adjusting the CCD camera's position to make the optical axis perpendicular to the model surface; thirdly, choosing appropriate field of view to ensure clear imaging of the model; fourthly, determining optical path; finally, recording the surface image of the model during excavation by the DDC camera.

4.3. The Principle ofDICM. After the simulation experiment, photos are analyzed in order to obtain the deformation and strain. In this process, the key is how to match the two 


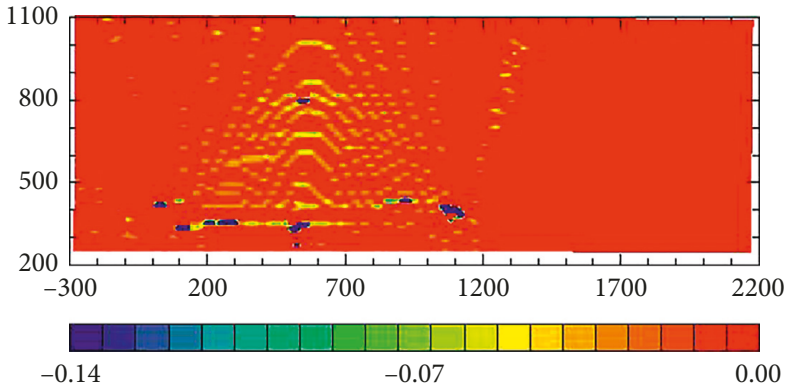

(a)

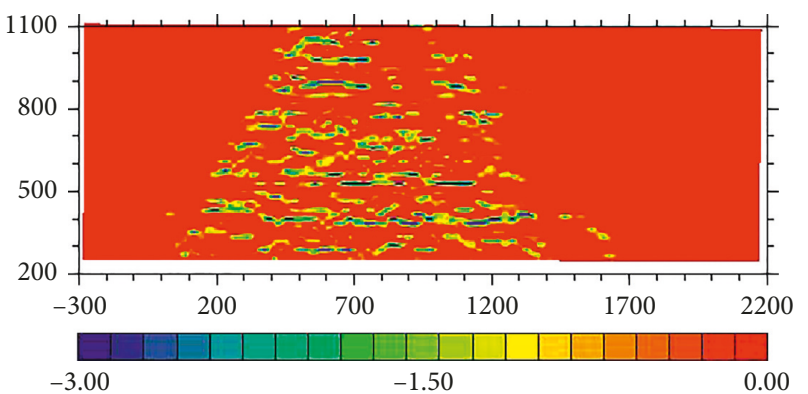

(c)

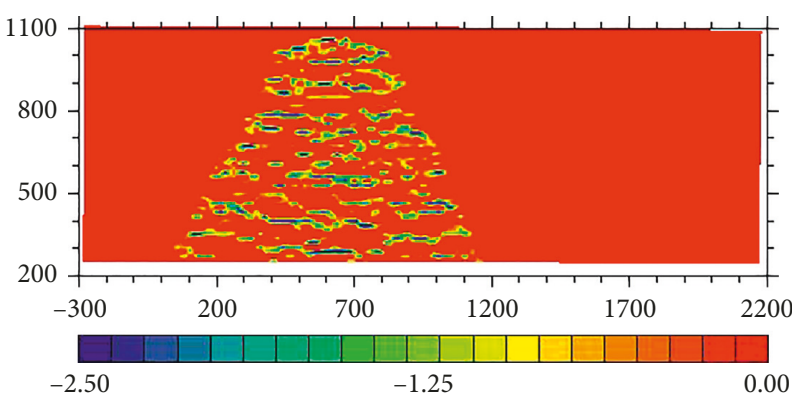

(b)

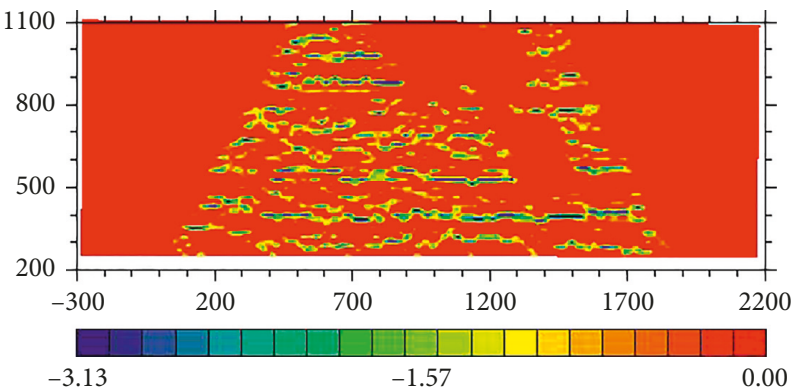

(d)

Figure 10: The distribution of vertical strain during excavation. The coal stratum is excavated to (a) $120 \mathrm{~m}$, (b) $130 \mathrm{~m}$, (c) $165 \mathrm{~m}$, and (d) $190 \mathrm{~m}$.

photos before and after deformation. First of all, defining the image before and after deformation as the base image and the target one, respectively (Figure 9); secondly, to trace the motion trajectory of the point $P$ in the base image, taking a subset $f$ from $P$ as a center and searching a most matched subset $g$ in the target image. The point $Q$ corresponding with $g$ in the target image is the location of $P$ after deformation. The coordinate difference between two points is the displacement of the point $P$.

According to the correlation principle of statistics, a correlation function $C$, which is used to express the matching degree of the two images before and after deformation, is established as follows:

$$
C=\frac{\sum \sum[(f-\bar{f}) \cdot(g-\bar{g})]}{\left[\sum \sum(f-\bar{f})^{2} \cdot \sum \sum(g-\bar{g})^{2}\right]^{1 / 2 .}}
$$

Generally, when $C=1$, the two images match each other exactly; while when $C=0$, the two images are uncorrelated.

4.4. The Analysis by DICM. As the excavation is carried out, photos are taken by the CCD camera, the recorded photos will be analyzed in order by the software GeoDIC, and the curves and figures of deformation and strain fields of the overlying strata are obtained by PostViewer, the result visualization postprocessing system. Sizes in this part are exaggerated by 1000 times, and the units of the excavation and deformation are meter.

4.4.1. Strain Field Analysis of the Overlying Strata. The vertical strain in the similar material simulation model distributes as Figure 10. An arched failure zone is formed before fracturing, it enlarges upwards, and then the failure zones distribute as layers with the excavation continuing (Figure 10(a)). The arches fracture continuously with the excavation going on. Tensile damage occurs at the lower surface of the thick overlying hard rock where cracks appear. Before the first weighting, the vertical strain distributes as arched layers. When the excavation is going on, the overlying strata cave periodically; after the periodic weighting, the vertical strain still distributes in layers (Figures 10(b)-10(d)).

The shearing strain distribution in the similar material simulation model is shown in Figure 11, the open cut and workface are forced by shearing force, and the shearing effect becomes more and more obvious with the excavation continuing. Shearing strain distributes in arched symmetrically, and shearing damage occurs at the open cut and workface (Figure 11(a)). The shearing strain closing to the ends of goaf is larger, and the shearing strain at the two ends are in the opposite directions. With the excavation continuing, the roof caves, shearing failure zones fracture, and the overlying yet unfractured shearing zones are still distributed as an arch, even though the periodic weighting happens (Figures 11(b)-11(d)).

4.4.2. Deformation Field Analysis of the Overlying Strata. The vertical displacement in the similar material simulation model distributes as Figure 12, which totally increases gradually with the excavation continuing. The deformation distributes in arch before roof caving (Figure 12(a)). With the excavation continuing, the first weighting happens and the roof caves; meantime, the deformation increases 


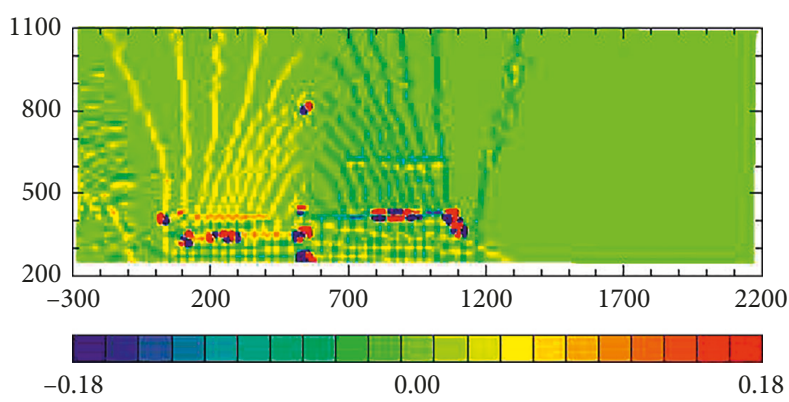

(a)

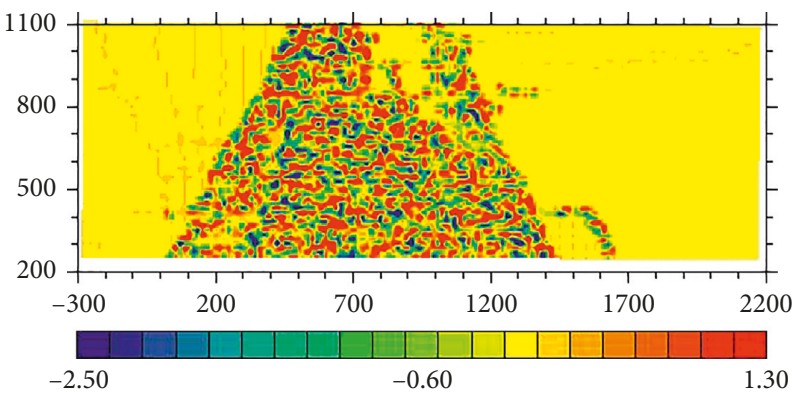

(c)

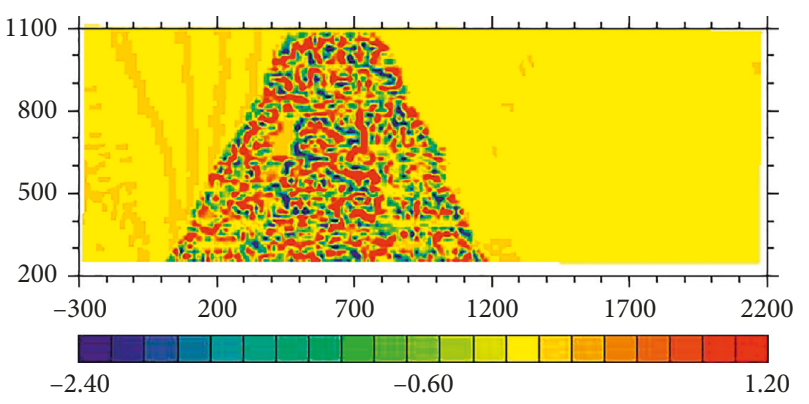

(b)

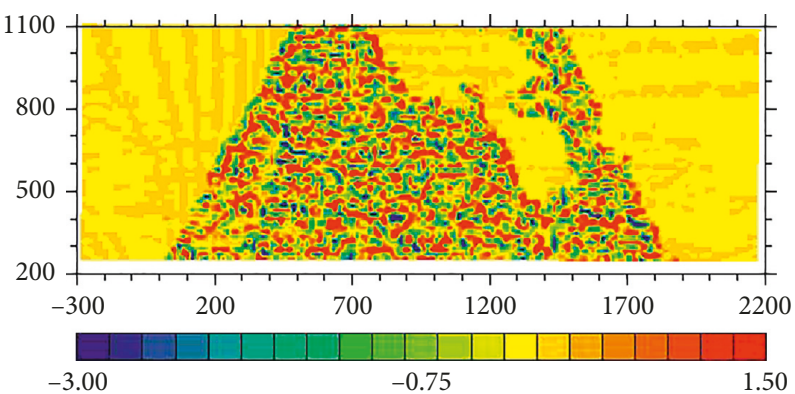

(d)

FIGURE 11: The distribution of shearing strain during excavation. The coal stratum is excavated to (a) $120 \mathrm{~m},(\mathrm{~b}) 130 \mathrm{~m}$, (c) $165 \mathrm{~m}$, and (d) $190 \mathrm{~m}$.

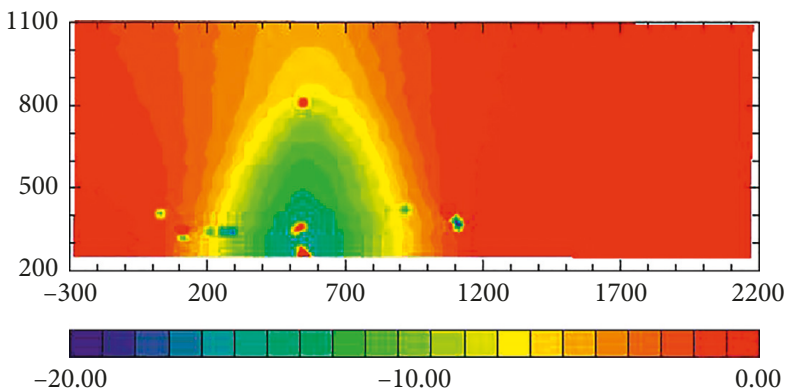

(a)

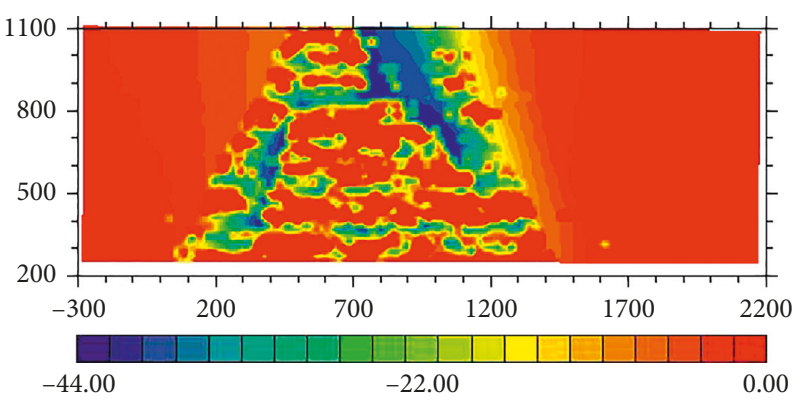

(c)

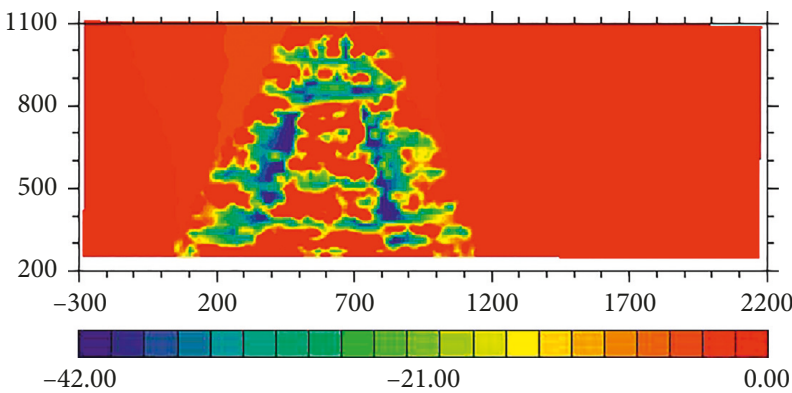

(b)

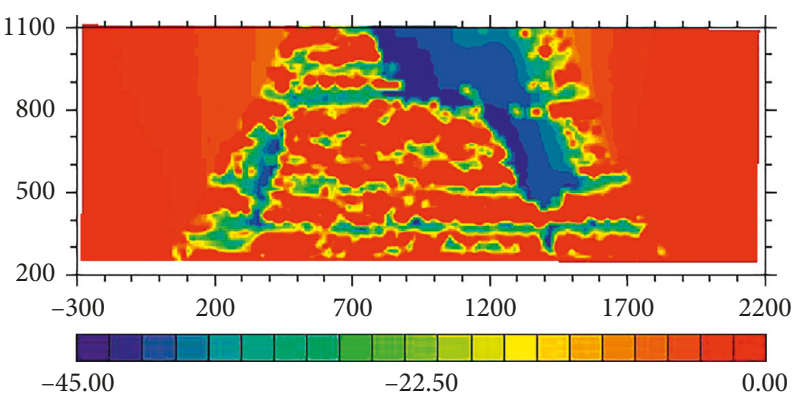

(d)

Figure 12: The distribution of vertical deformation during excavation. The coal stratum is excavated to (a) $120 \mathrm{~m}$, (b) $130 \mathrm{~m}$, (c) $165 \mathrm{~m}$, and (d) $190 \mathrm{~m}$.

rapidly, and the caved roof has compacted on the floor (Figure 12(b)). When excavation is going on (Figures 12(c) and $12(\mathrm{~d})$ ), the first periodic weighting and second periodic weighting happen, the roof fractures and caves periodically, and the vertical deformation behind workface increases quickly. During periodic weightings, the maximal deformation appears far away from the coal stratum, the roof compacts on the floor, relatively speaking, the deformation in the thick overlying hard rock and those closed strata have smaller increments, and strata which are far away 


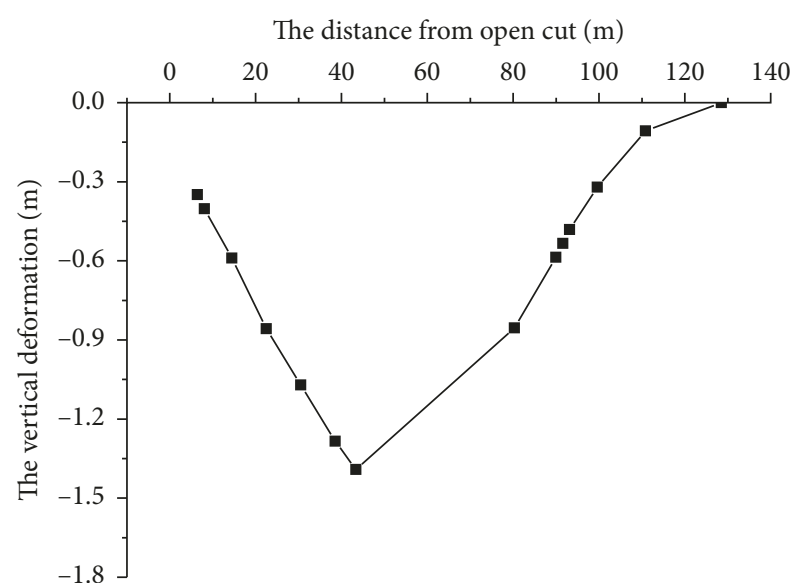

(a)

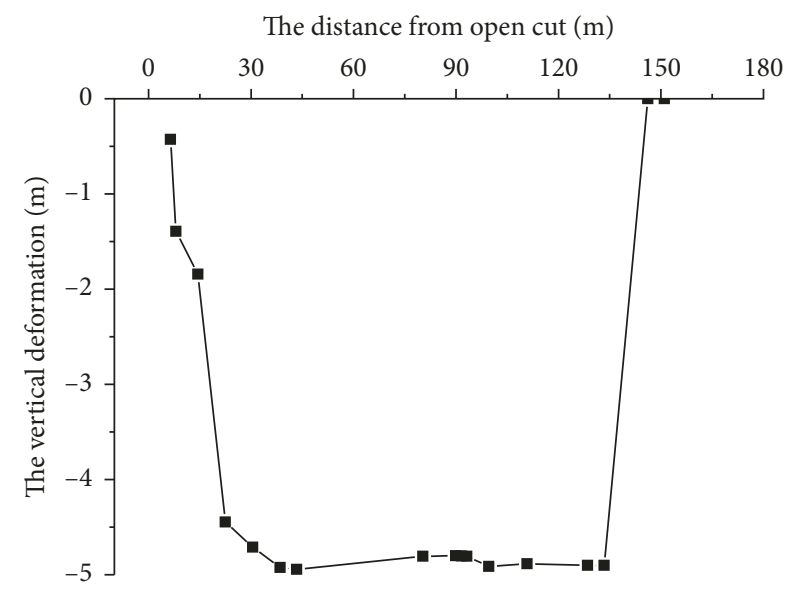

(c)

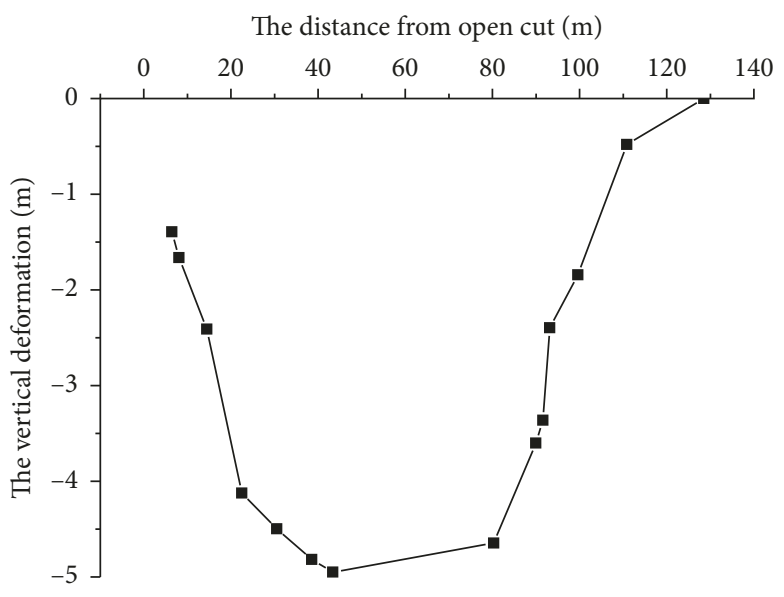

(b)

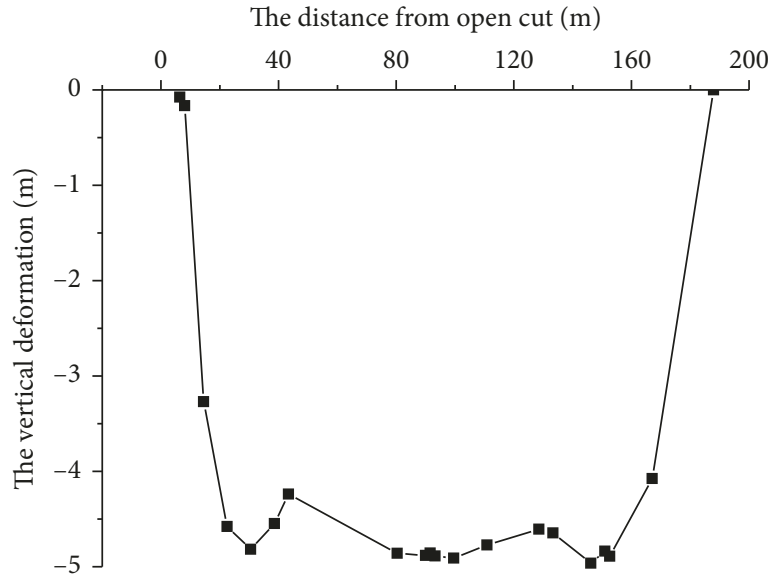

(d)

FIGURE 13: The vertical deformation of the test points during excavation. The coal stratum is excavated to (a) $120 \mathrm{~m}$, (b) $130 \mathrm{~m}$, (c) $165 \mathrm{~m}$, and (d) $190 \mathrm{~m}$.

from the excavated coal stratum have larger deformation increments.

Twenty testing points are chosen to analyze the deformation field of the overlying strata, buried in a line, $1.5 \mathrm{~m}$ above the excavated coal stratum. The vertical deformation of these points during excavation is collected and curves are drawn as in Figure 13.

With the excavation continuing to $120 \mathrm{~m}$, the roof subsides, but it has not fractured (Figure 13(a)). The subsidence of the roof starting from the open cut first increases then decreases, which is the same with the deflection curve of beam under pressure. The maximal subsidence is approximately $1.391 \mathrm{~m}$, appearing at the middle of the roof and approximately $42 \mathrm{~m}$ away from the open cut. The subsiding speed is slow and almost equal, and there is nearly no subsidence in the roof about $110 \mathrm{~m}$ away from the open cut.

The first weighting happens when the coal stratum is excavated $130 \mathrm{~m}$, and the subsidence increases obviously (Figure 13(b)). The maximal subsidence appears at the range of about $40 \mathrm{~m}$ to $87 \mathrm{~m}$ away from the open cut, and the peak value is approximately $5 \mathrm{~m}$ and is equal to the thickness of the excavated coal stratum, which means the caved roof has compacted on the floor. It has nearly no subsidence about $130 \mathrm{~m}$ away from the open cut.

When the first periodic weighting happens, the maximal subsidence appears about $40 \mathrm{~m}$ to $135 \mathrm{~m}$ away from the open cut, and the peak value is also $5 \mathrm{~m}$ (Figure 13(c)). Comparing with Figure 13(b), the caved and compacted roof adds $48 \mathrm{~m}$. The subsidence of the roof increases at the range of $100 \mathrm{~m}$ to $140 \mathrm{~m}$ away from the open cut, and there is nearly no subsidence in the roof about $150 \mathrm{~m}$ away from the open cut.

As workface is pushed onto $190 \mathrm{~m}$, the second periodic weighting happens, and the maximal subsidence is approximately $5 \mathrm{~m}$, appearing from $40 \mathrm{~m}$ to about $170 \mathrm{~m}$ away from the open cut (Figure 13(d)). Comparing with Figure 13(b), the subsidence of the roof at the range of $140 \mathrm{~m}$ to $190 \mathrm{~m}$ away from the open cut increases; especially, the subsiding speed increases rapidly at the range of $150 \mathrm{~m}$ to $170 \mathrm{~m}$ away from the open cut, and it has nearly no subsidence in the roof about $200 \mathrm{~m}$ away from the open cut.

4.5. Accuracy Analysis. In order to verify the accuracy of the DICM in the similar material simulation experiments, we 


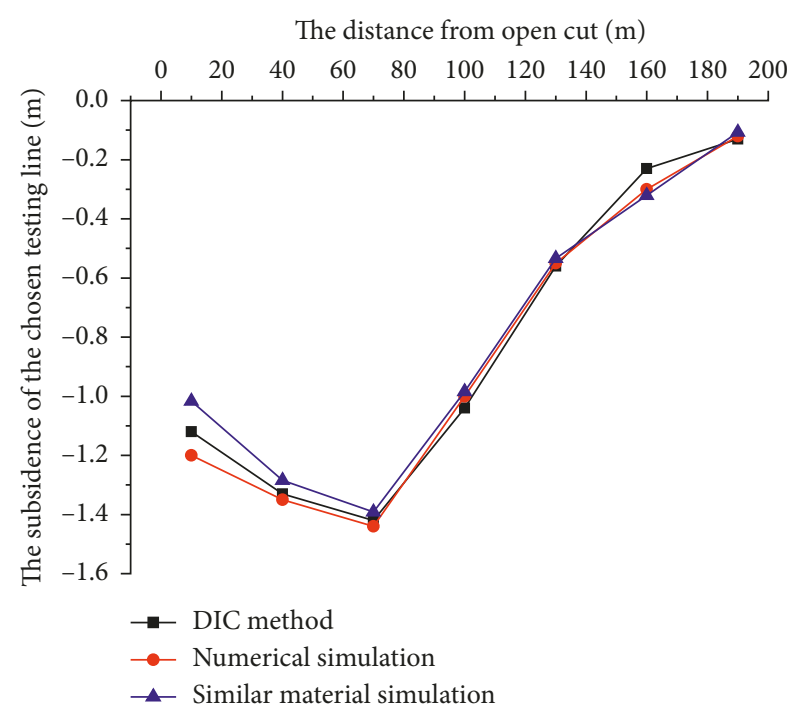

Figure 14: Accuracy analysis.

make a comparative analysis on the subsidence of 7 points in a row, $36 \mathrm{~m}$ away from the excavated coal stratum in the thick overlying hard rock, when the workface is pushed onto $120 \mathrm{~m}$. Results are obtained and tested by the DICM, numerical simulation, and the displace sensors in the similar material simulation model.

The obtained subsiding lines are shown and compared in Figure 14. It is found that the result of the DICM is in accordance with the testing results obtained by numerical simulation and similar material simulation, which means the DICM used in the large scale full-field deformation measurement on complex rock structure is entirely feasible.

\section{Conclusions}

The no. 1 borehole of the VI strata in a coal field in North China is simulated by similar material simulation experiment, and the DICM is introduced in this test to study the fracturing rule, stress field, and deformation field on roof with good unity. The failure forms of the overlying strata and the fracture development characteristics are observed and studied. The distribution of stress, strain, and deformation in the overlying strata are tested and analyzed. The accuracy of the DICM is verified. The following conclusions are obtained:

(1) Based on the similar material simulation experiment, the movement of the overlying strata during excavation is observed. The thick overlying hard rock fractures with obvious dynamic pressure. An unstable three-hinged rock arch is formed as the caved thick overlying hard rock interlocked with each other at the open cut and workface. Due to the good integrity and continuity of the thick roof, it fractures and caves in a hole when periodic weightings happen. The overlying strata are controlled by the thick overlying hard rock because the thick overlying hard rock and the overlying strata move synchronously before and after fracturing. So that, whether the thick overlying hard rock fractures or not has a direct effect on the fracture of the overlying strata.

(2) Based on the DICM, the distributions of strain and deformation of the overlying strata during excavation are obtained, and the influence on the overlying strata's fracture and movement is analyzed. An arched failure zone forms before fracturing, it enlarges upwards, and the failure zones distribute as layers with the excavation continuing. The arches fracture continuously with the excavation going on. Tensile damage occurs at the lower surface of the thick overlying hard rock where cracks appear, and shearing damage appears at the open cut and workface. The thick overlying hard rock has the maximal subsidence and the fastest subsiding speed.

(3) DICM used in the large-scale full-field deformation measurement on complex rock structure is in accordance with the testing results obtained by numerical simulation and similar material simulation and is entirely feasible. The DICM directly reproduces the movement and fracturing process of the overlying strata during excavation. It overcomes the weakness of similar material simulation experiments, and it reflects the characteristics of locality and randomness of rock-like materials more real than numerical simulation.

\section{Conflicts of Interest}

The authors declare that there are no conflicts of interest regarding the publication of this paper.

\section{Acknowledgments}

This work is supported by the Natural Science Foundation of Jiangsu Province of China (BK20160433 and BK20160437), the National Natural Science Fund (11502229), the Outstanding Young Backbone Teacher of QingLan Project in Jiangsu Province, Jiangsu Government Scholarship for Overseas Studies, Scholarship for Overseas Studies in Yancheng Institute of Technology, and the Program of Outstanding Young Scholars in Yancheng Institute of Technology.

\section{References}

[1] I. Yamaguchi, "Speckle displacement and deformation in the diffraction and image fields for small object deformation," Optica Acta: International Journal of Optics, vol. 28, no. 10, pp. 1359-1376, 1981.

[2] W. H. Peters and W. F. Ranson, "Digital imaging techniques on experimental stress analysis," Optical Engineering, vol. 21, no. 3, pp. 427-432, 1982.

[3] W. H. Peters, W. F. Ranson, M. A. Sutton, and J. Anderson, "Application of digital correlation methods to rigid body mechanics," Optical Engineering, vol. 22, no. 6, pp. 738-742, 1983.

[4] Y. H. Zhao, H. H. Liang, C. Y. Xiong, and J. Fang, "Deformation measurement of rock damage by digital image correlation method," Chinese Journal of Rock Mechanics and Engineering, vol. 21, no. 1, pp. 73-76, 2002. 
[5] S. W. Hao, M. F. Xia, F. J. Ke, and Y. L. Bai, "Evolution of localized damage zone in heterogeneous media," International Journal of Damage Mechanics, vol. 19, no. 7, pp. 787-804, 2010.

[6] S. W. Hao, H. Y. Wang, M. F. Xia, F. J. Ke, and Y. L. Bai, "Relationship between strain localization and catastrophic rupture," Theoretical and Applied Fracture Mechanics, vol. 48, no. 1, pp. 41-49, 2007.

[7] S. Q. Yang, D. S. Yang, H. W. Jing, Y. H. Li, and S. Y. Wang, "An experimental study of the fracture coalescence behaviour of brittle sandstone specimens containing three fissures," Rock Mechanics and Rock Engineering, vol. 45, no. 4, pp. 563-582, 2012.

[8] S. Q. Yang and H. W. Jing, "Strength failure and crack coalescence behavior of brittle sandstone samples containing a single fissure under uniaxial compression," International Journal of Fracture, vol. 168, no. 2, pp. 227-250, 2011.

[9] C. Zhao, H. Matsuda, C. Morita, and M. R. Shen, "Study on failure characteristic of rock-like materials with an open-hole under uniaxial compression," Strain, vol. 47, no. 5, pp. 405-413, 2011.

[10] Y. S. Ma, W. Z. Chen, D. S. Yang, J. P. Yang, and Z. Gong, "Experimental study of brittle rock failure based on threedimensional digital image correlation technique," Rock and Soil Mechanics, vol. 38, no. 1, pp. 117-123, 2017.

[11] G. Gao, S. Huang, K. Xia, and Z. Li, “Application of digital image correlation (DIC) in dynamic notched semi-circular bend (NSCB) tests," Experimental Mechanics, vol. 55, no. 1, pp. 95-104, 2015.

[12] G. Gao, W. Yao, K. Xia, and Z. Li, "Investigation of the rate dependence of fracture propagation in rocks using digital image correlation (DIC) method," Engineering Fracture Mechanics, vol. 138, pp. 146-155, 2015.

[13] S. P. Ma, D. Yan, X. Wang, and Y. Y. Cao, "Damage observation and analysis of a rock Brazilian disc using highspeed DIC method," Applied Mechanics and Materials, vol. 70, pp. 87-92, 2011.

[14] Y. M. Song, S. P. Ma, X. B. Yang, and X. Wang, "Experimental investigation on failure of rock by digital speckle correlation methods," Chinese Journal of Rock Mechanics and Engineering, vol. 30, no. 1, pp. 170-175, 2011.

[15] J. Dautriat, N. Gland, A. Dimanov, and J. L. Raphanel, "Hydromechanical behavior of heterogeneous carbonate rock under proportional triaxial loadings," Journal of Geophysical Research: Solid Earth, vol. 116, no. B1, pp. 1-10, 2011.

[16] J. Dautriat, M. Bornert, N. Gland, A. Dimanov, and J. L. Raphanel, "Localized deformation induced by heterogeneities in porous carbonate analysed by multi-scale digital image correlation," Tectonophysics, vol. 503, no. 1-2, pp. 100-116, 2011.

[17] J. L. Cheng, S. Q. Yang, K. Chen, D. Ma, F.-Y. Li, and L.-M. Wang, "Uniaxial experimental study of the acoustic emission and deformation behavior of composite rock based on 3D digital image correlation (DIC)," Acta Mechanica Sinica, vol. 33, no. 6, pp. 999-1021, 2017.

[18] S. Hedan, P. Cosenza, V. Valle, P. Dudoignon, A.-L. Fauchille, and J. Cabrerac, "Investigation of the damage induced by desiccation and heating of Tournemire argillites using digital image correlation," International Journal of Rock Mechanics and Mining Science, vol. 51, pp. 64-75, 2012.

[19] B. F. Li, Y. J. Zuo, W. Li, and J. Cao, "Analysis on fracture mechanics of granite containing flaws based on digital image processing," Mechanics in Engineering, vol. 38, no. 2, pp. 262268, 2016.

[20] D. Yang, M. Bornert, S. Chanchole, H. Gharbi, P. Valli, and B. Gatmiri, "Dependence of elastic properties of argillaceous rocks on moisture content investigated with optical full-field strain measurement techniques," International Journal of Rock Mechanics \& Mining Science, vol. 53, pp. 45-55, 2012.

[21] D. Yang, M. Bornert, S. Chanchole, L. Wang, P. Valli, and B. Gatmiri, "Experimental investigation of the delayed behavior of unsaturated argillaceous rocks by means of digital image correlation techniques," Applied Clay Science, vol. 54, no. 1, pp. 53-62, 2011.

[22] X. B. Wang, Y. Z. Du, Y. S. Pan, and L. Gu, "Measurement of shear bands of sand specimens with different water contents under constant strain rate based on digital image correlation method," Rock and Soil Mechanics, vol. 36, no. 3, pp. 625-632, 2015.

[23] X. B. Wang, Y. Z. Du, and Y. S. Pan, "Experimental studies of strain distribution and strain gradients for sand specimens in uniaxial compression based on the digital image correlation with coarse-fine search method," Chinese Journal of Geotechnical Engineering, vol. 34, no. 11, pp. 2050-2057, 2012.

[24] X. B. Wang, Y. Z. Du, and Y. S. Pan, "Measurements of local and global volumetric strains for wet sand specimens under uniaxial compression using digital image correlation method," Chinese Journal of Geotechnical Engineering, vol. 36, no. 9, pp. 1648-1656, 2014.

[25] L. Zinsmeister, J. Dautriat, A. Dimanov, J. Raphanel, and M. Bornert, "Mechanical evolution of an altered limestone using 2D and 3D digital image correlation (DIC)," in Proceedings of the 47th US Rock Mechanics/Geomechanics Symposium, vol. 4, pp. 2965-2979, San Francisco, CA, USA, June 2013.

[26] A. L. Fauchille, S. Hedan, D. Prêt, P. Cosenza, V. Valle, and J. Cabrera, "Relationships between desiccation cracking behavior and microstructure of the Tournemire clay-rock by coupling DIC and SEM methods," in Proceedings of the TC105 ISSMGE International Symposium on Geomechanics from Micro to Macro, IS-Cambridge, vol. 2, pp. 1421-1424, Cambridge, UK, September 2014.

[27] A. L. Fauchille, S. Hedan, V. Valle, D. Pret, J. Cabrera, and P. Cosenza, "Multi-scale study on the deformation and fracture evolution of clay rock sample subjected to desiccation," Applied Clay Science, vol. 132-133, pp. 251-260, 2016.

[28] S. Hedan, A. L. Fauchille, V. Valle, J. Cabrera, and P. Cosenza, "One-year monitoring of desiccation cracks in Tournemire argillites using digital image correlation," International Journal of Rock Mechanics and Mining Science, vol. 68, pp. 22-35, 2014.

[29] S. Chen, Z. Q. Yue, and L. G. Tham, "Digital image based numerical modeling method for heterogeneous geomaterials," Chinese Journal of Geotechnical Engineering, vol. 27, no. 8, pp. 956-964, 2005.

[30] Z. Q. Yue, "Digital representation of meso-geomaterial spatial distribution and associated numerical analysis of geomechanics: methods, applications and developments," Chinese Journal of Rock Mechanics and Engineering, vol. 25, no. 5, pp. 875-888, 2006.

[31] M. Bornert, F. Brémand, P. Doumalin et al., "Assessment of digital image correlation measurement errors: methodology and results," Experimental Mechanics, vol. 49, no. 3, pp. 353370, 2009.

[32] T. L. Nguyen, S. A. Hall, P. Vacher, and G. Viggiani, "Fracture mechanism material simulation in soft rock: identification and quantification of evolving displacement discontinuities by extended digital image correlation," Tectonophysics, vol. 503, no. 1-2, pp. 117-128, 2011.

[33] V. Valle, S. Hedan, P. Cosenza, A. L. Fauchille, and M. Berdjane, "Digital image correlation development for study of materials 
including multiple crossing cracks," Experimental Mechanics, vol. 55, no. 2, pp. 379-391, 2015.

[34] Y. Chen, J. X. Wei, H. L. Huang, W. Jin, and Q. J. Yu, "Application of 3D-DIC to characterize the effect of aggregate size and volume on non-uniform shrinkage strain distribution in concrete," Cement and Concrete Composites, vol. 86, pp. 178-189, 2018.

[35] C. G. Su, D. Liu, C. X. Ding, C. Gong, P. Zhao, and X. Liu, "Experimental study on bond performances of track slab and mortar based on DIC technology," KSCE Journal of Civil Engineering, vol. 10, pp. 1-10, 2018.

[36] L. T. Mao, X. X. Zhu, L. Q. An, G. S. Cai, and N. Hao, "Application of digital target marker image correlation method in model experiment," Journal of Liaoning Technical University, vol. 32, no. 10, pp. 1367-1373, 2013.

[37] H. Wang, Z. Y. Zhu, H. Z. Liu, and L. T. Mao, “Application of digital target marker correlation method and digital image correlation method in model experiment," in Proceedings of the 23th Annual Conference of the Beijing Mechanical Association, 2017 USTB, pp. 453-454, Beijing, China, 2017.

[38] C. J. Guo, C. Q. Nan, and D. Wang, "Similar material simulation experiment on overburden rock movement of closedistance coal seams," Metal Mine, vol. 463, pp. 10-15, 2015.

[39] H. C. Li, Similar Simulation Test of Mine Pressure, China University of Mining and Technology Press, Xuzhou, China, 1988.

[40] F. Gao, K. P. Zhou, W. J. Dong, and J. H. Su, "Similar material simulation of time series system for induced caving of roof in continuous mining under backfill," Journal of Central South University of Technology, vol. 15, no. 3, pp. 356-360, 2008.

[41] H. W. Wang, H. W. Zhou, J. P. Zuo, Z. G. Wang, and H. P. Xie, "Application of optical measurement method in strata movement simulation experiment," Journal of China Coal Society, vol. 31, no. 3, pp. 278-281, 2006.

[42] H. Yanli, Z. Jixiong, A. Baifu, and Z. Qiang, "Overlying strata movement law in fully mechanized coal mining and backfilling longwall face by similar physical simulation," Journal of Mining Science, vol. 47, no. 5, pp. 618-627, 2011. 


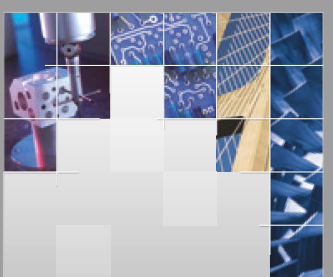

\section{Enfincering}
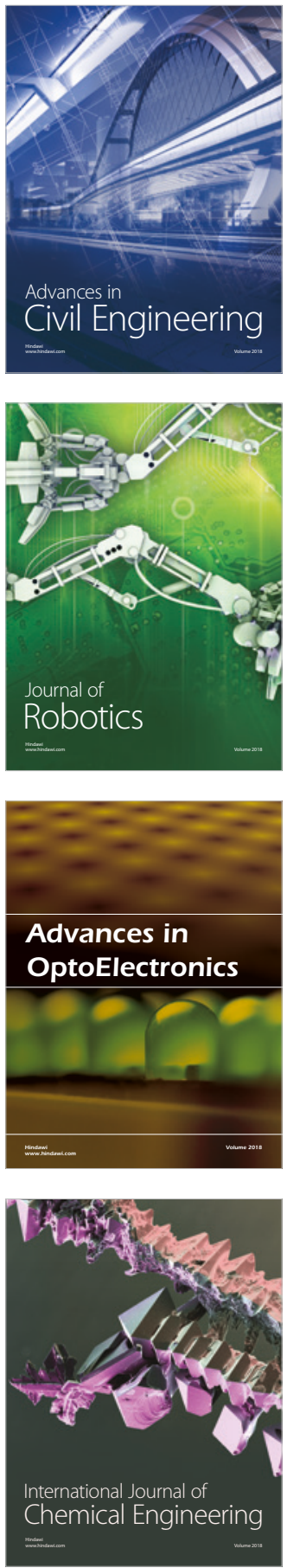

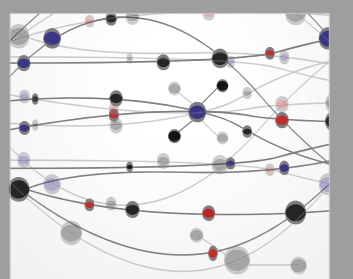

\section{Rotating \\ Machinery}

The Scientific World Journal

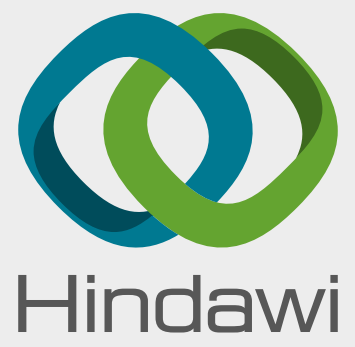

Submit your manuscripts at

www.hindawi.com
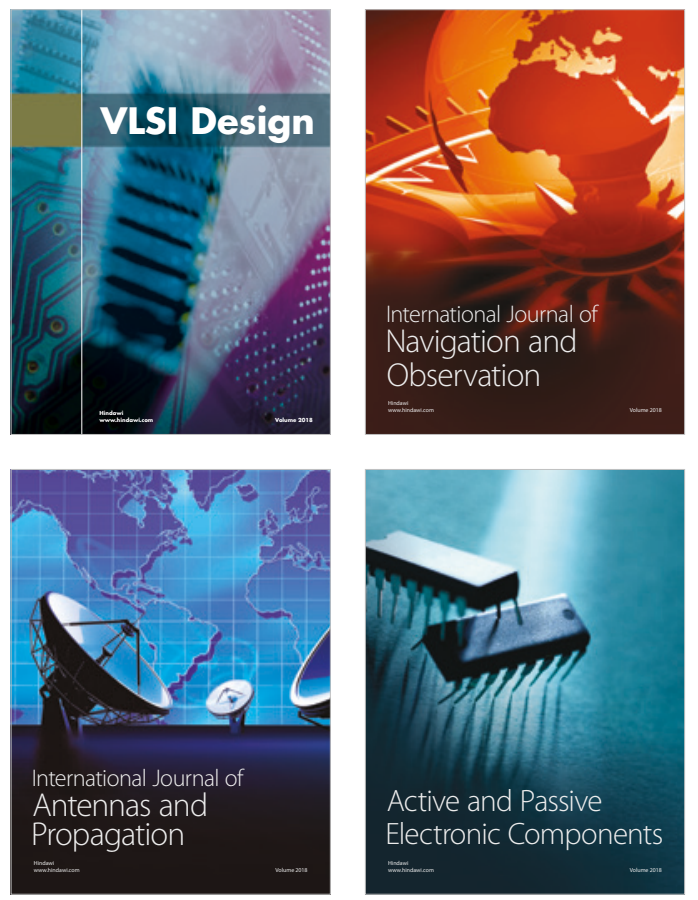
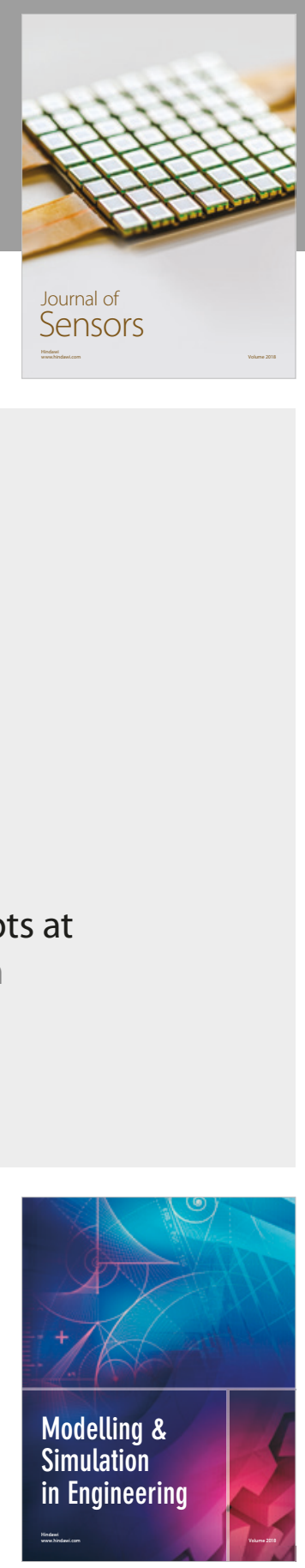

\section{Advances \\ Multimedia}
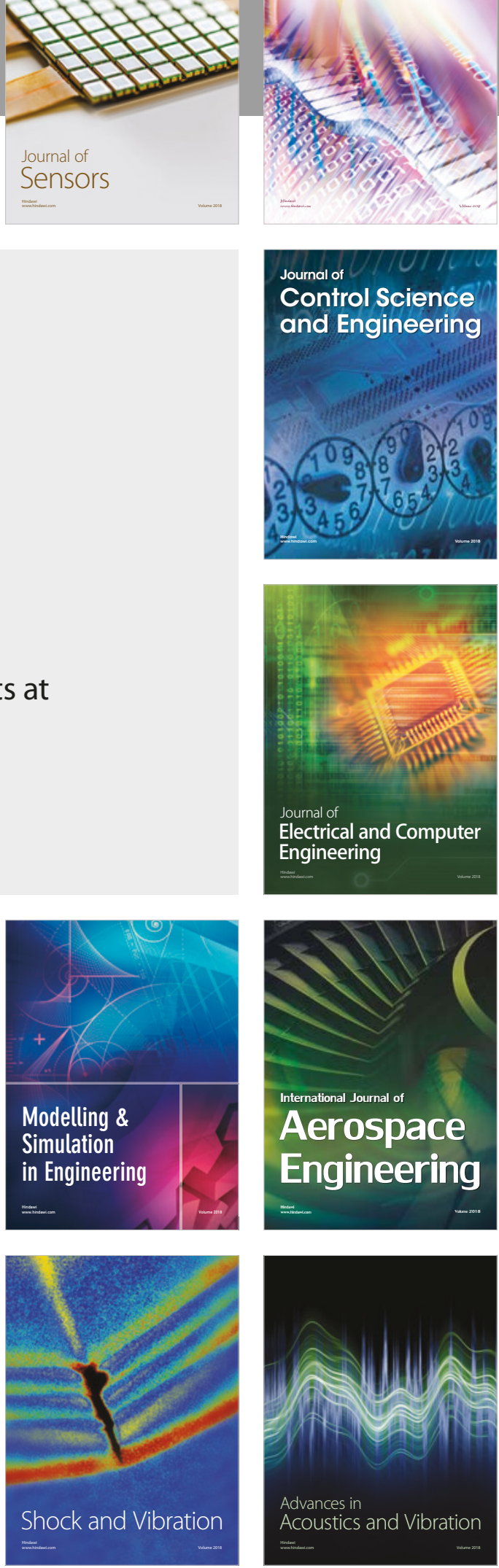